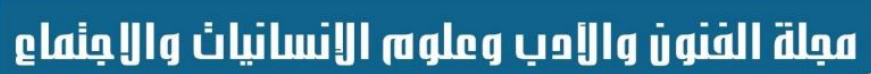 Journal of Arts, Literature, Humanities \\ and Social Sciences
}

ISSN print: 2616- 3810

ISSN online: 2414 - 3383

Volume 48

January 2020
¿ÁLHSS

www.jalhss.com
(48) - العدد (40)

يناير 2020

\section{الأسطح الطباعية في تعزيز التكامل الحسي للأطفال المكفوفين تيزين}

\author{
باحث رئيس: هوازن عبد المنتصر شاقعي

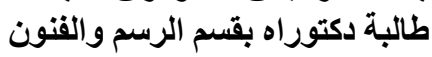 \\ hali0027.stu@uj.edu.sa:الايميل
}

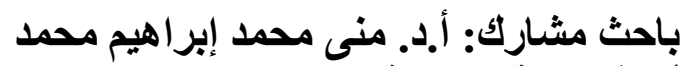
أستاذ الطباعة والصباغة بقسم الرسم والفنون الايميل:momohamed@uj.edu.sa

باحث مشارك: أ.د. تبرة جميل طه خصيفان أستاذ الأشغال الفنية بقسم الرسم و الفنون tjkhusaifan@uj.edu.sa:الايميل

كلية التصاميم والفنون - جامعة جدة ــ المملكة العربية السعودية

الملخص

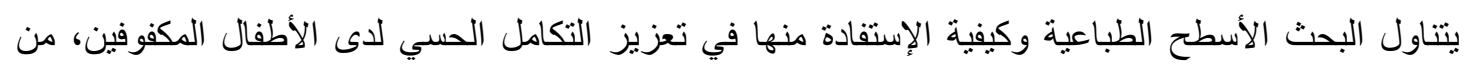

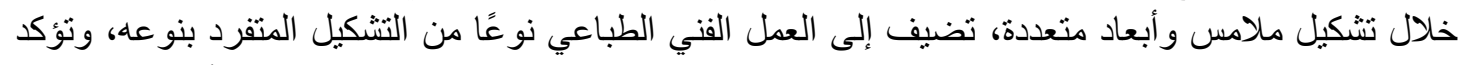

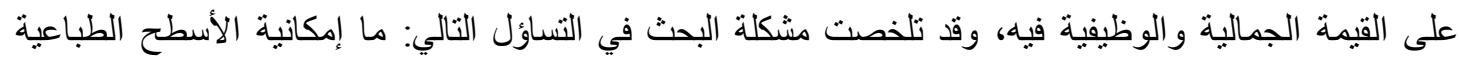

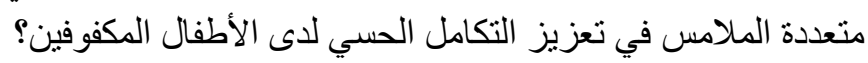

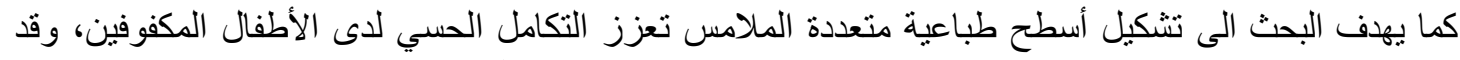

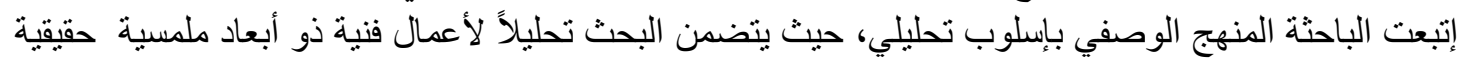

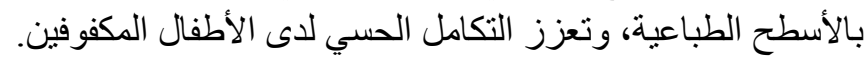

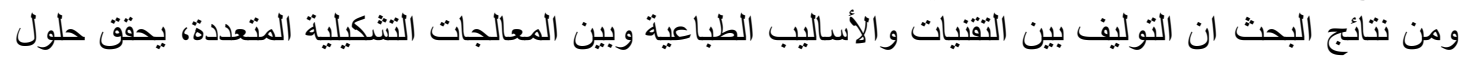

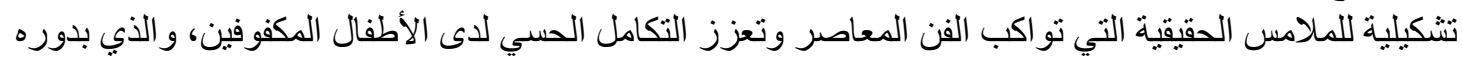
يتم من خلال إثراء المدرك الحسي وتطوير مهارة إستخدام حاسة اللمس كوسيلة تعرف الكفيف على الكي البيئة المحيطة من حوله.

وتوصي الباحثة بالإفادة من الدراسة الحالية في تشكيل الأسطح الطباعية متعددة الملامس و المعالجات التشكيلية

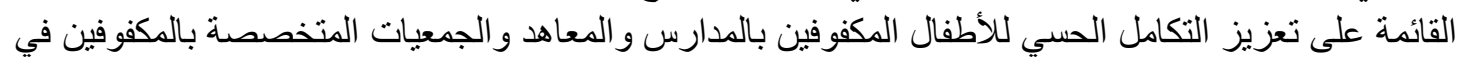
المملكة العربية السعودية، وفي العالم اجمع العية.

الكلمات المفتاحية: الأسطح الطباعية ، ملامس السطح الطباعي ، التكامل الحسي ، الكف البصري. 


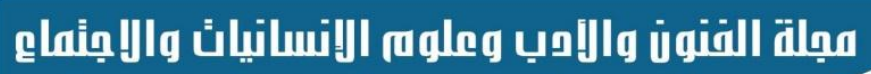

Journal of Arts, Literature, Humanities

and Social Sciences

ISSN print: 2616- 3810

Volume 48

ISSN online: 2414 - 3383

January 2020

\section{Printing Surfaces In Enhances Sensory Integration for Blind Children}

\author{
Hawazin A. Shafie \\ Email: hali0027.stu@uj.edu.sa \\ Dr. Muna Muhammed I. Muhammed \\ Email:momohamed@uj.edu.sa
}

Dr. Tebra J. Tha Khusifan

Email:tjkhusaifan@uj.edu.sa

University of Jeddah - College of Design and Art - Drawing and Art Department

\begin{abstract}
The research deals with the printing surfaces in enhances sensory integration for blind children by forming multiple texture and dimensions, that adds to the print artwork a kind of unique composition, and it emphasizes the aesthetic and functional value of it. The research problem was summarized in the following question: What is the potential for multi-touch printing surfaces to enhance sensory integration in blind children?

The research also aims to form multi-touch surfaces that enhance sensory integration in blind children, and it followed the descriptive approach in an analytical way, that includes an analysis of works of art with real touch dimensions on the printing surfaces.

One of the results of the research is that the synthesis between printing techniques and fine art

Formulations achieves formative solutions for real touches that keep up with contemporary art, and enhance sensory integration in blind children, Which in turn is enriched by sensory perception, and develop the skill of using the sense of touch as a means of identifying the blind to the surrounding environment.

The researcher recommends the use of the current study in the formation of multiple print surfaces based on enhancing sensory integration of blind children in schools, institutes and specialized associations for the blind in Saudi Arabia and all over the world.
\end{abstract}

Keywords: Print surfaces, Printed textured surfaces, Sensory integration , Optical blindness. 


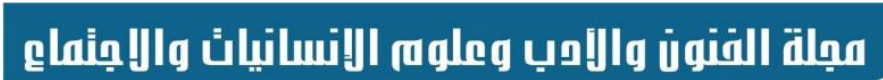 Journal of Arts, Literature, Humanities \\ and Social Sciences}

ISSN print: 2616- 3810

ISSN online: 2414 - 3383
Volume 48

January 2020

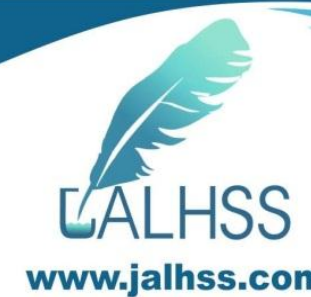

(48) (48)

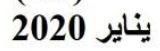

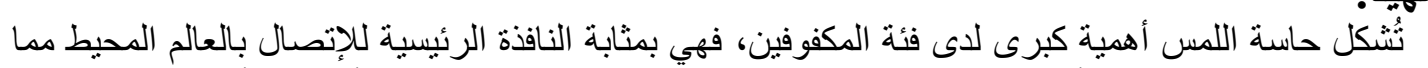

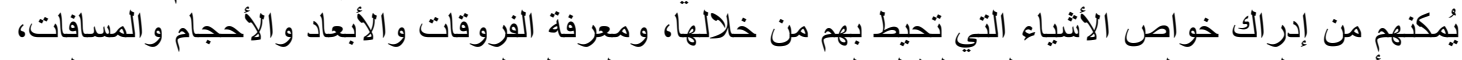

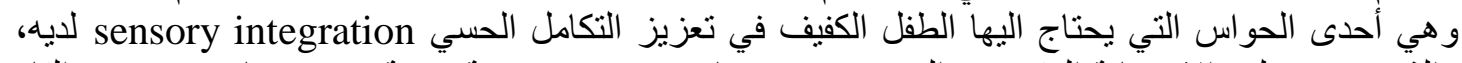

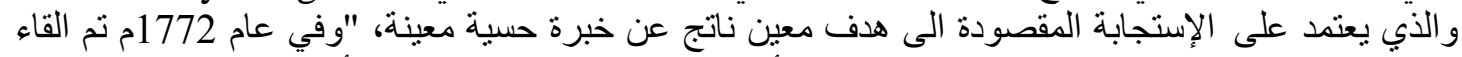

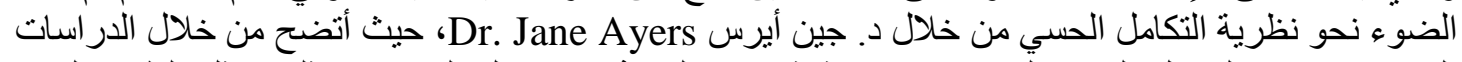

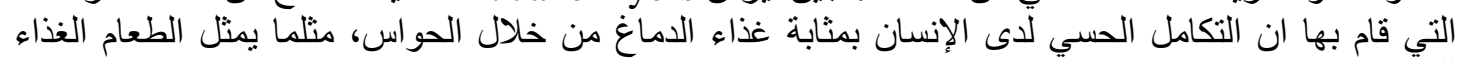

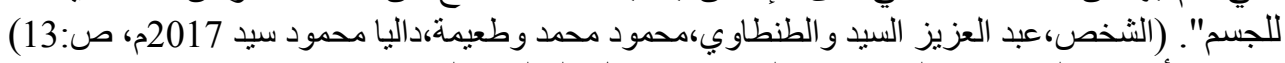

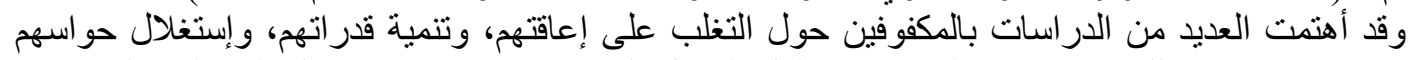

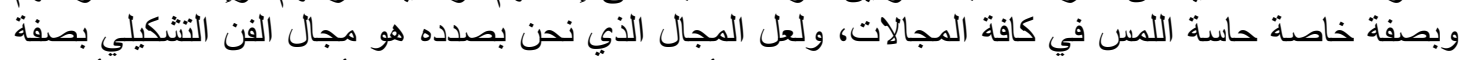

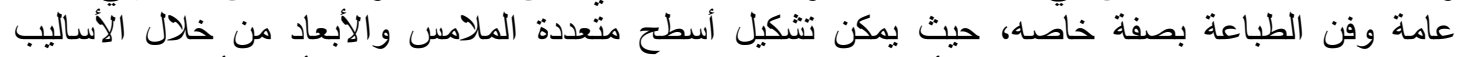

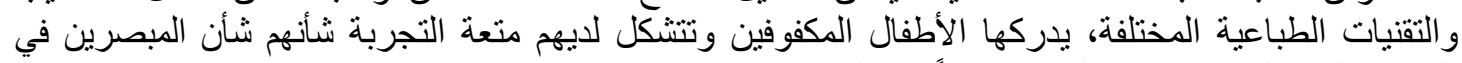

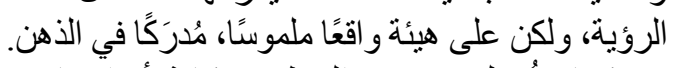

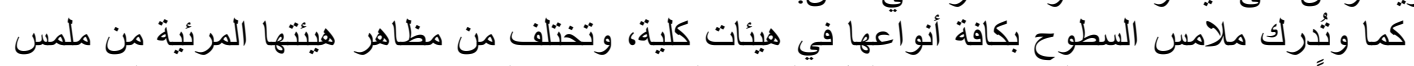

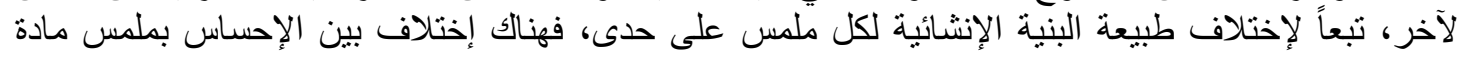

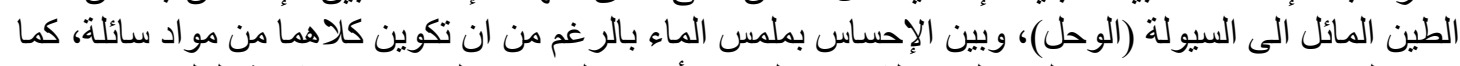

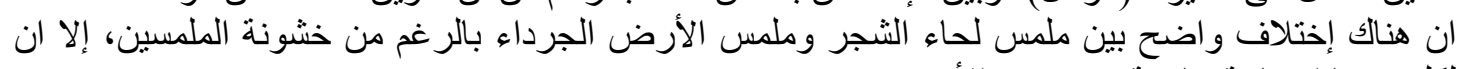

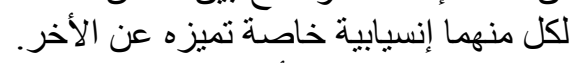

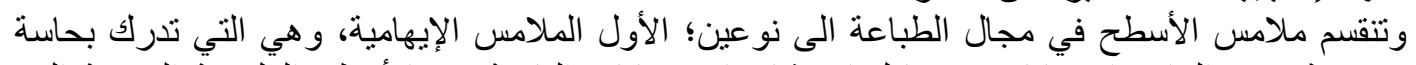

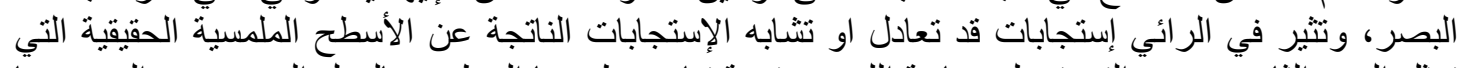

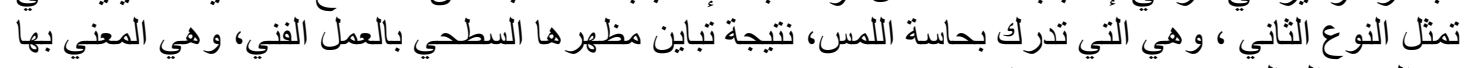

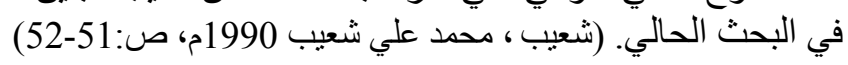

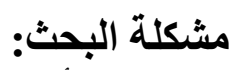
ما إمكانية الأسطح الطباعية متعددة الملامس في تعزيز التكامل الحسي لاى الأطفال المكفوفين؟

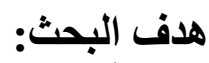
تشكيل أسطح طباعية متعددة الملامس تعزز التكامل الحسي لدى الأطفال المكفوفين.

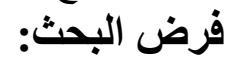
يمكن تعزيز التكامل الحسي لدى الأطفال المكفوفين من خلال الأسطح الطباعية متعددة الملامس. أهمية البحث: أعزيز النكان:

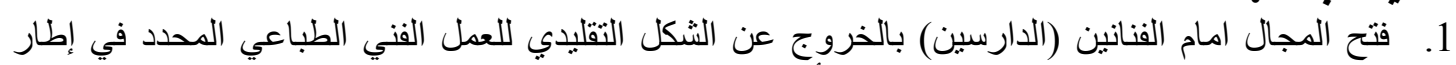

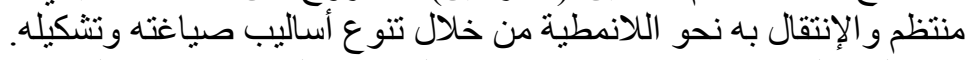

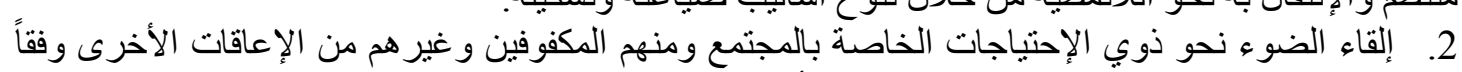

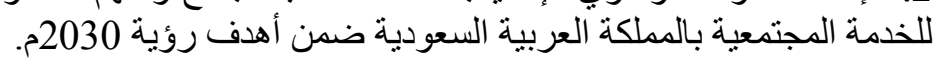
3. السعي الى الإستفادة من التقنيات الطباعية الحديثة في تعزيز الثرفية التكامل الحسي لدى الأطفال المكفوفين. حدود موضوعية تتمثل في: مفهوم الأسطح الطباعية ـ ملامس السطح الطباعي- مفهوم التكامل الحسي-

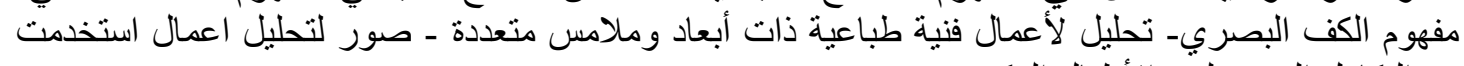

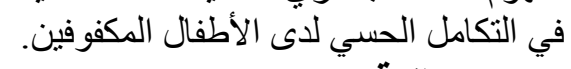
حذود مكانية: المملكة العربية السعودية.

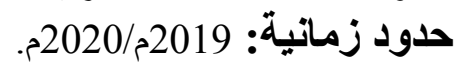




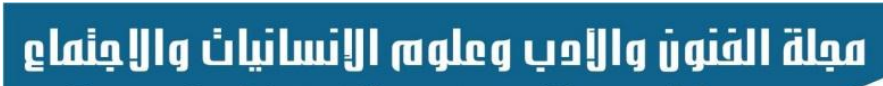 Journal of Arts, Literature, Humanities \\ and Social Sciences}

ISSN print: 2616- 3810

ISSN online: 2414 - 3383

\section{Volume 48 January 2020 \\ LALLHSS www.jalhss.com

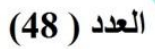 \\ يناير 2020}

$$
\text { مصطهاتة البحث: يتبع البحث المنهج الوصفي بأسلوب تحليلي. }
$$

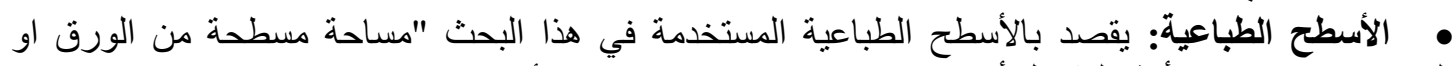

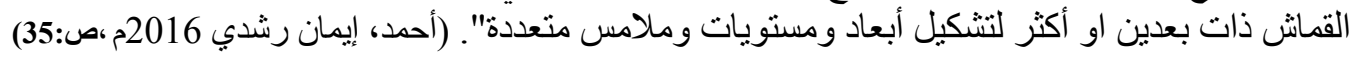

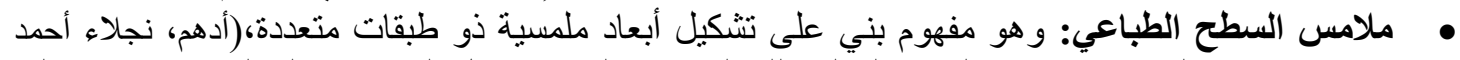

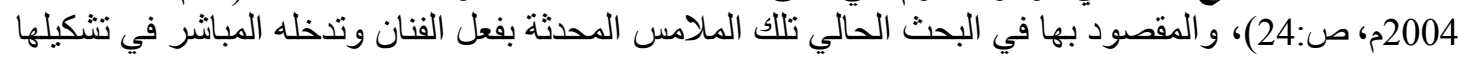

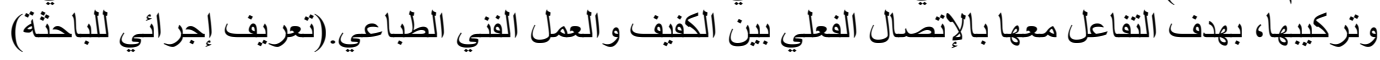

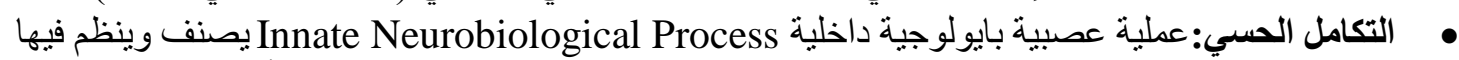

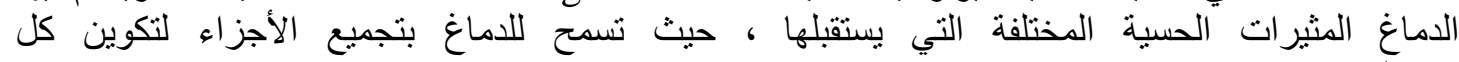

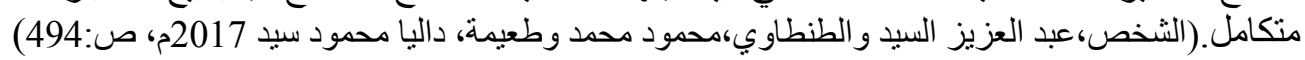

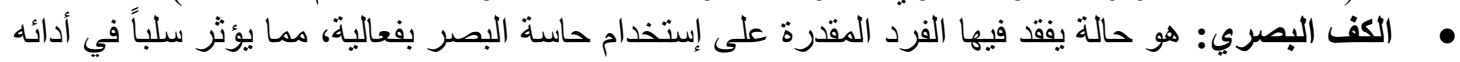

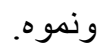
كما ذكر بأنه ضعف في أي من الوظائف البصرية الخمسة وهي؛ البصر المركزي، البصر المحيطي، البهري، التكيف

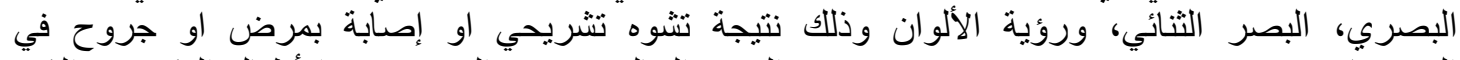

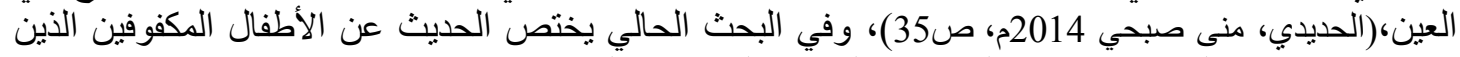
يندرجو ضمن فئة المكفوفين و لا يختلفون عن المفاهيم التي تم تناولثها.

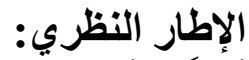

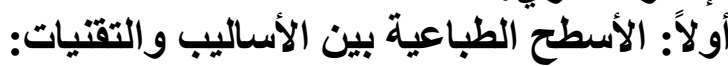

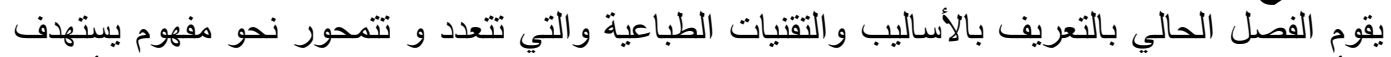

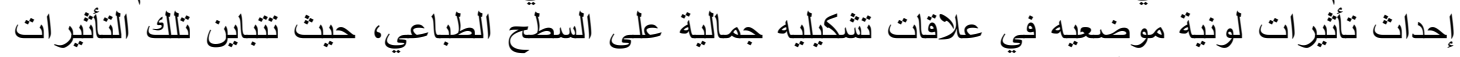

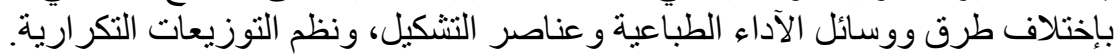

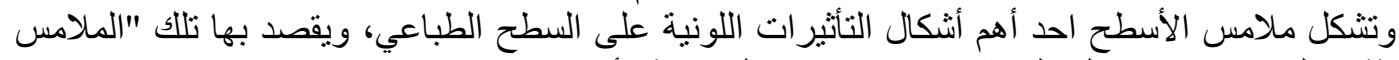

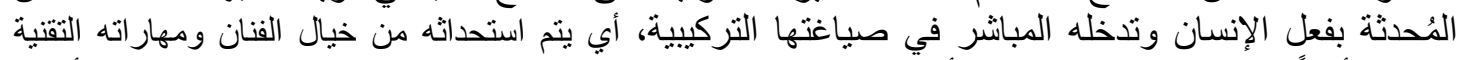

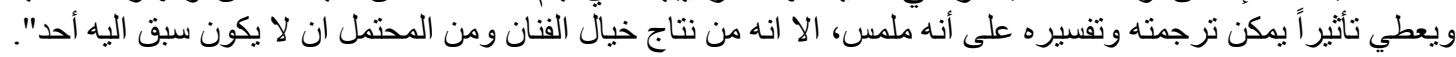

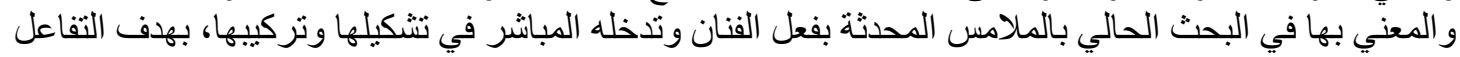

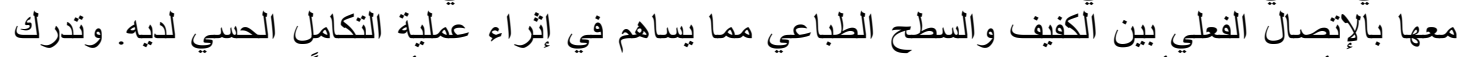

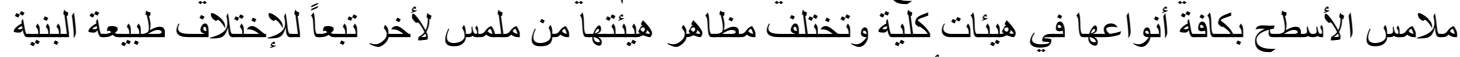

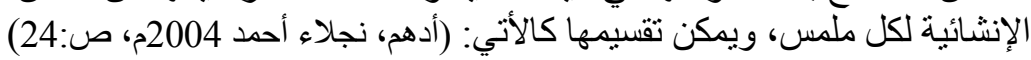

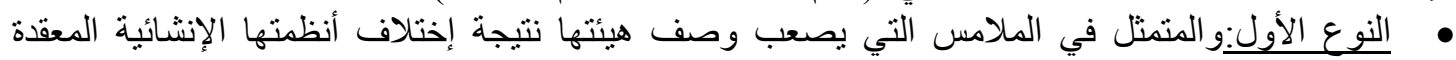

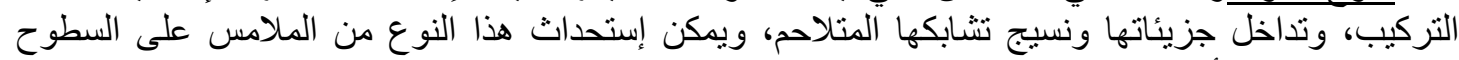
الطباعية بتقنيات و أدو ات وخامات ونتات مختلفة.

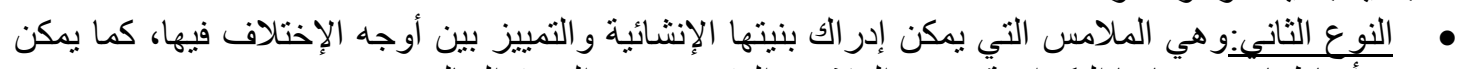

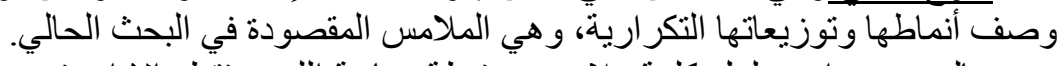

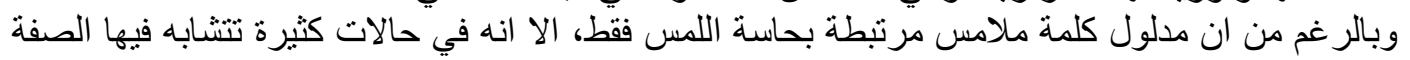

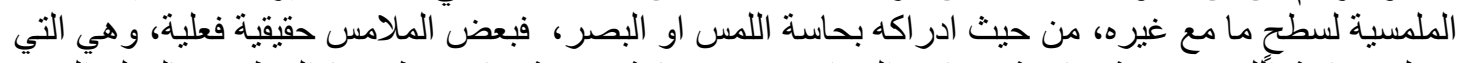

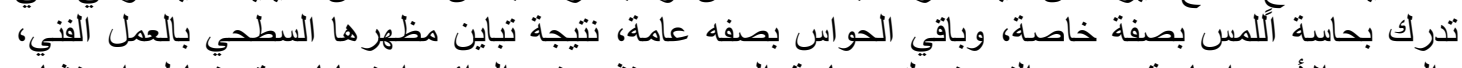

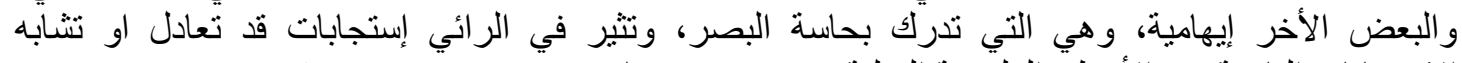

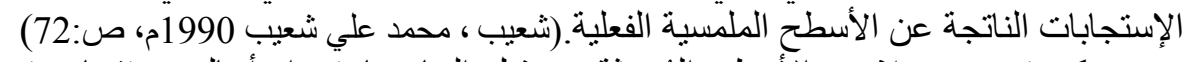

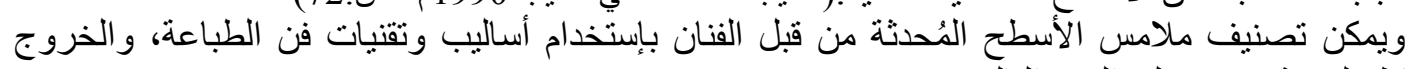
بأنماط ملمسية عديدة على النحو التالي: التحمي: 


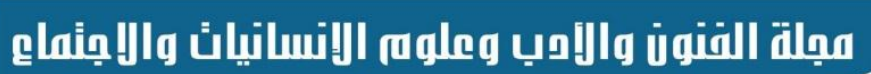 Journal of Arts, Literature, Humanities \\ and Social Sciences}

ISSN print: 2616- 3810

ISSN online: 2414 - 3383

Volume 48 January 2020
¿ÁLHSS

www.jalhss.com
(48) (العدد (4)

يناير 2020

أو لا:الأسطح الطباعية الناتجة عن التوليف بين مجال الطباعة ومجالات فنية أخرى.

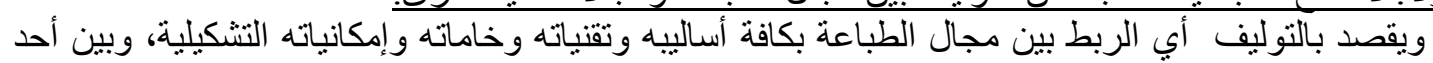
مجالات التعبير الفني الأخرى كالنحت أو التصوين مجئ التصوير أو الأشغال الفنية.

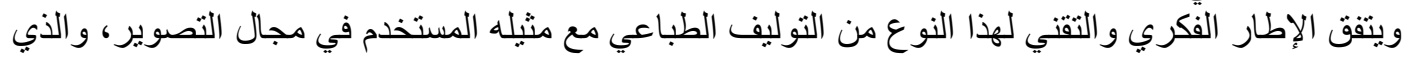
يعتمد على الجمع و المز اوجة بين مجمو عة مختلفة من الخامات الطبيعية او المصنعة بلفي بعد تشكيلها بطرق مختلفة

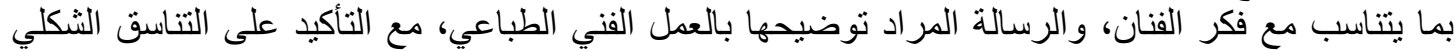

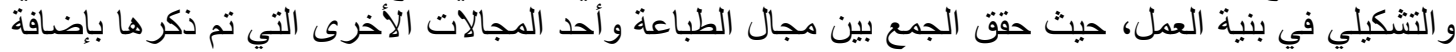

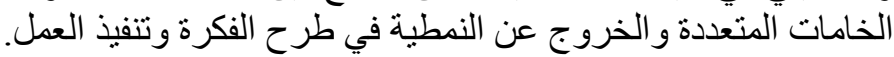

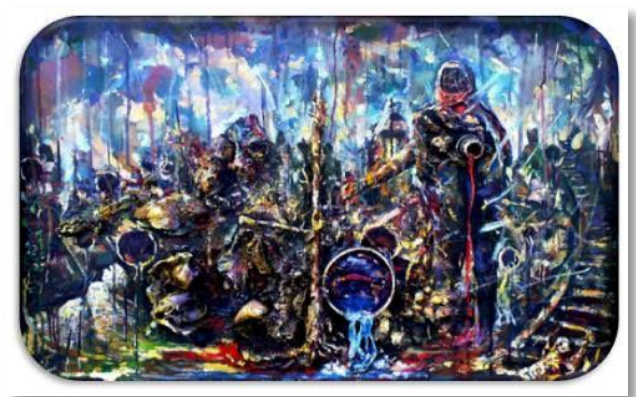

صورة رقم (1) توضح عمل فني تثكيلي تصويري بإسلوب الطباعة المباثرة

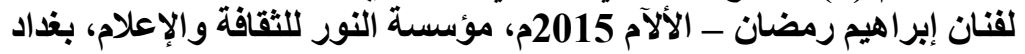
(http://new.alnoor.se/article.asp?id=278402)

ثانياً: الأسطح الطباعية الناتجة عن المز ج بين الأساليب و التقنيات الطباعية التقليدية و الحديثة.

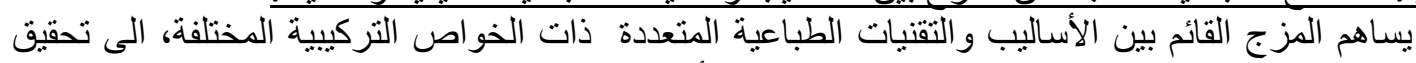

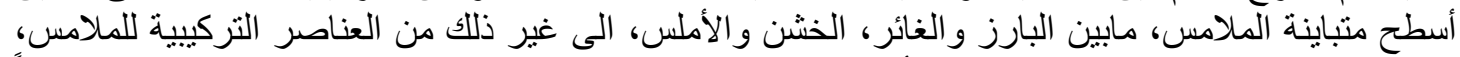

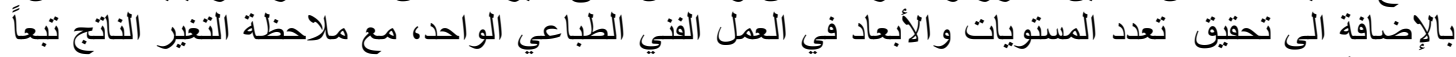

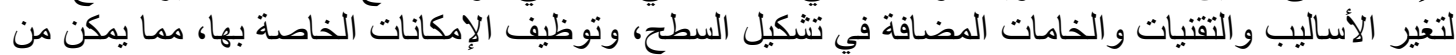

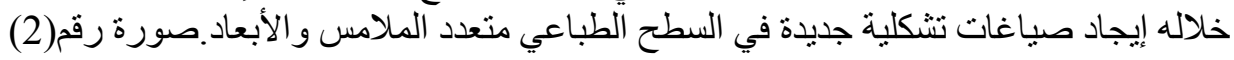

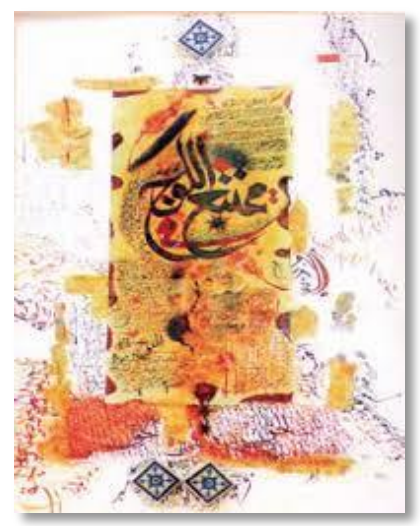

صورة رقم (2) توضح عمل فني تشكيلي طباعي منفذ بالمزج بين إسلوب الشاشة الحريرية و إسلوب الطباعة

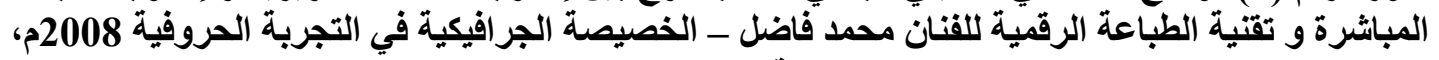
مجلة نزوى، عمان

(http://www.nizwa.com/pdf/Nizwa-56.pdf) 


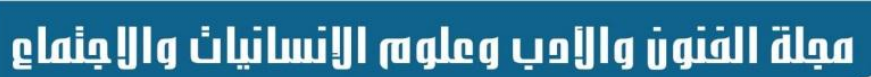 Journal of Arts, Literature, Humanities \\ and Social Sciences}

ISSN print: 2616- 3810

ISSN online: 2414 - 3383
Volume 48

January 2020
¿ALHSS www.jalhss.com

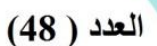

يناير 2020

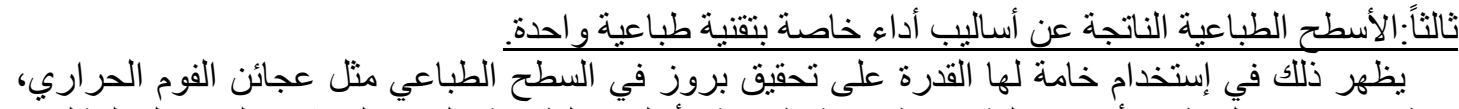

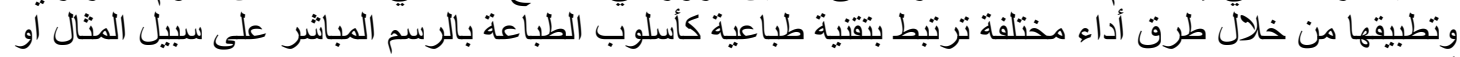

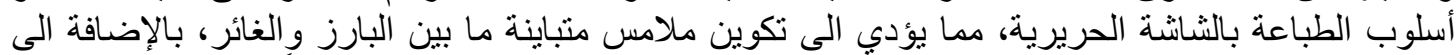

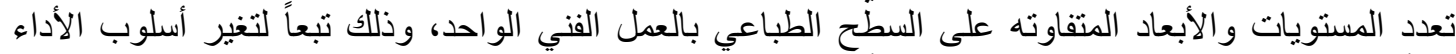

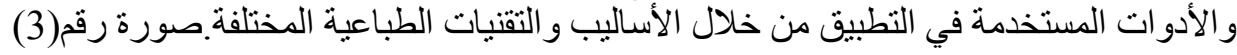

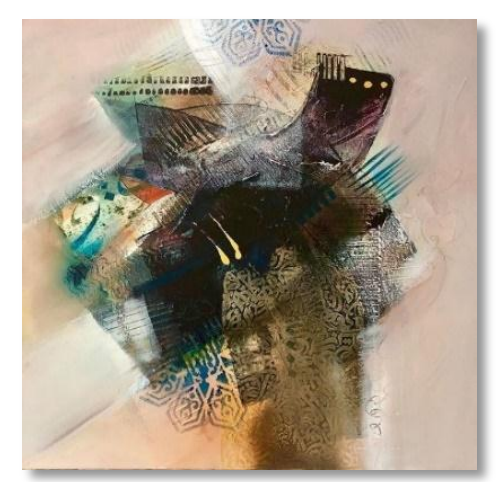

صورة رقم (3) توضح عمل فني تثكيلي طباعي منفذ بإسلوب الثاشة الحريرية وخامة الفوم الحراري، للفنان

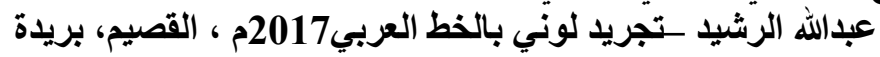

(https://www.instagram.com/artalrsheed/)

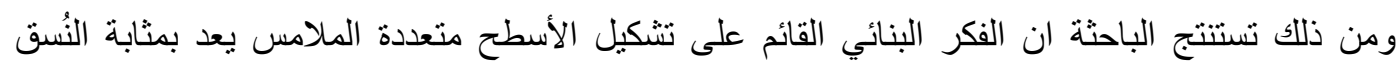

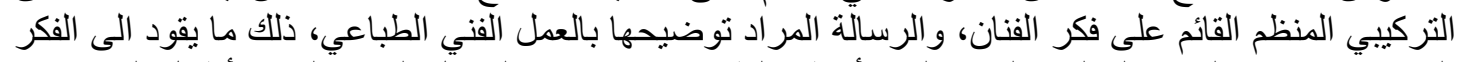

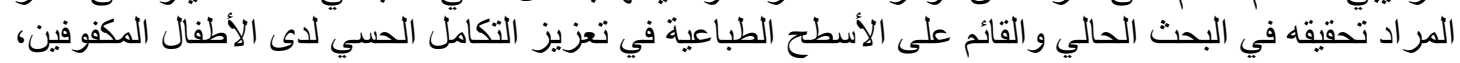

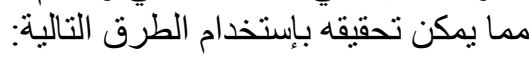

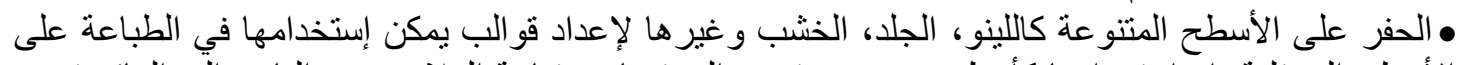

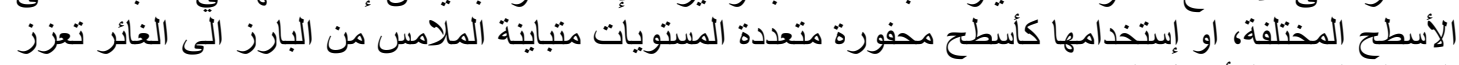
المدرك الحسي للأطفال المكفوفين.

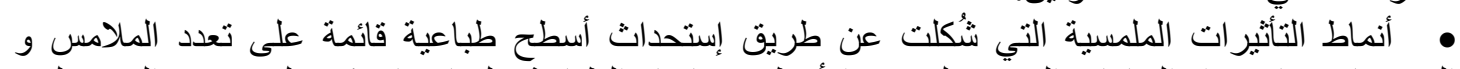

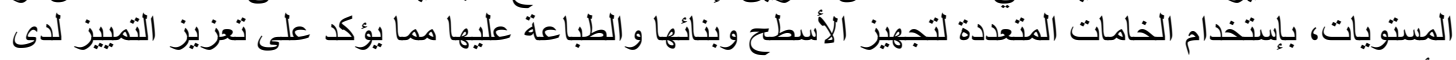

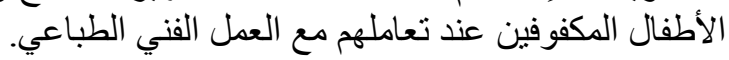

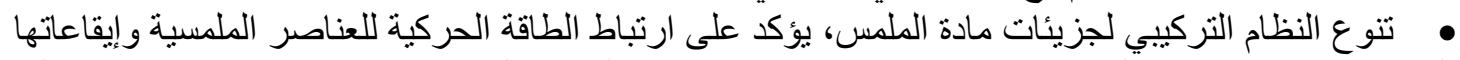

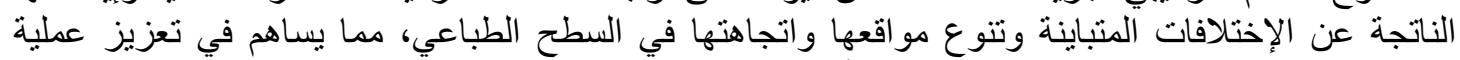

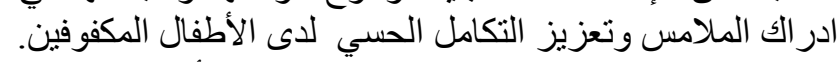

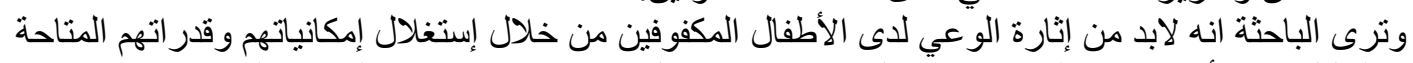

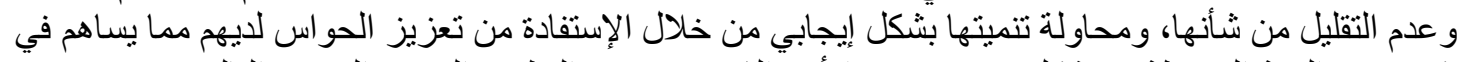

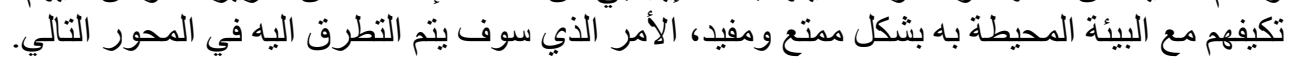

ثانياً: العلاقة بين ملامس الأسطح الطباعية وبين تعزيز التكامل الحسي لاى اللأطفال المكفوفين 


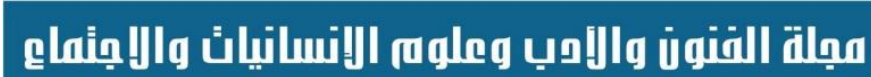 Journal of Arts, Literature, Humanities and Social Sciences \\ ISSN print: 2616- 3810 \\ ISSN online: 2414 - 3383 \\ Volume 48 January 2020 \\ ¿ALHSS www.jalhss.com \\ (48) - العدد (48) \\ يناير 2020}

يقوم الفصل الحالي بتوضيح العلاقة بين ملامس الأسطح الطباعية ومدى علاقتها بتعزيز التكامل الحسي لدى التى وذئ

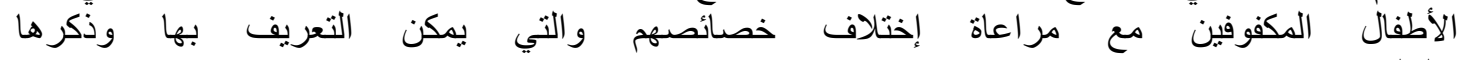
كالتالي:(http://www.alnafsy.com/،http://kenanaonline.com/users/Blindkids/posts/497497) 1. الخصائص النفسية: وهي المتعلقة بشخصية الطفل ونموه الوجداني والإنفعالي، العاطفي والإجتماعي،

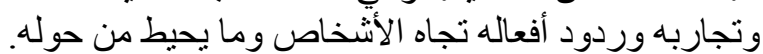

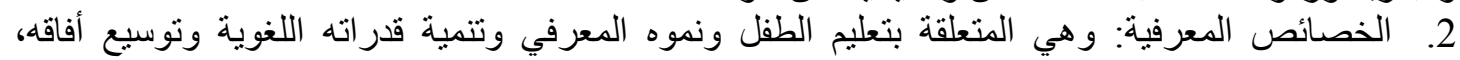
و إكتسابه الخبر ات من البيئة المحيطة: الخيطة.

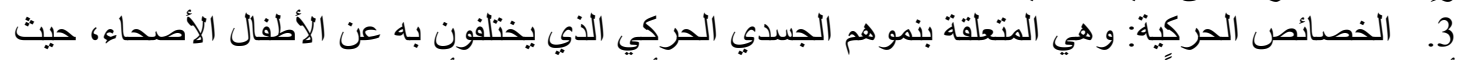

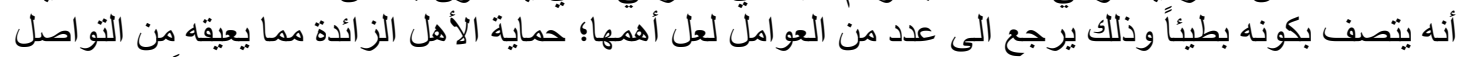

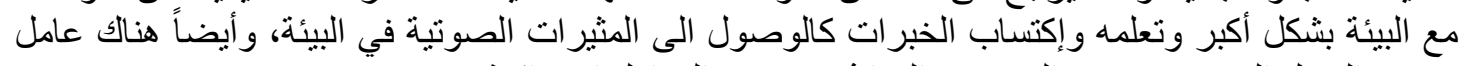

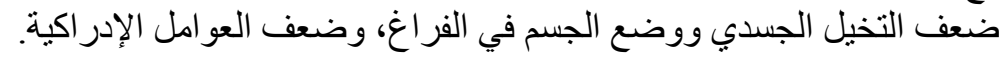

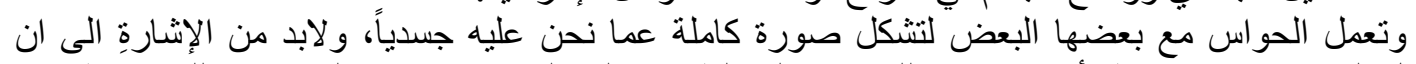

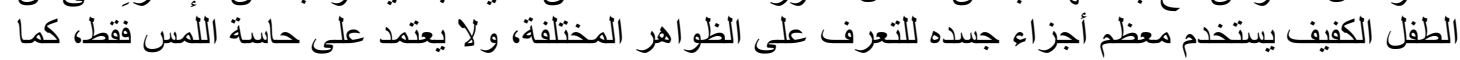

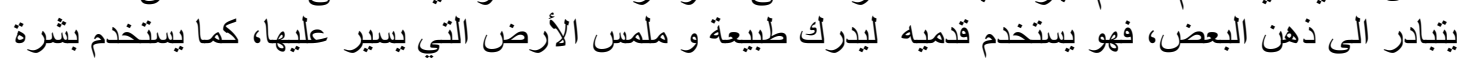

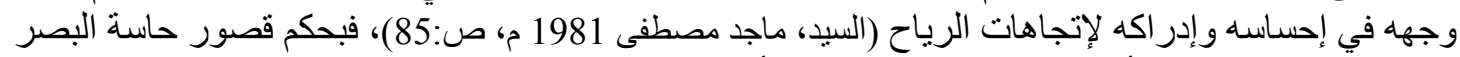

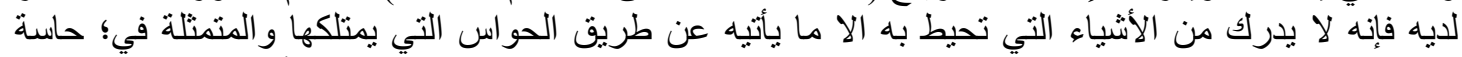

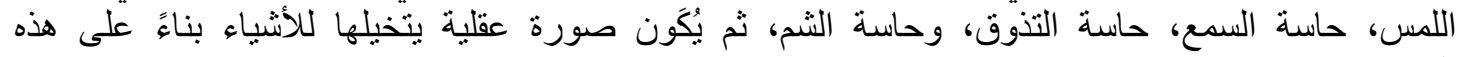

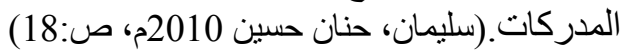

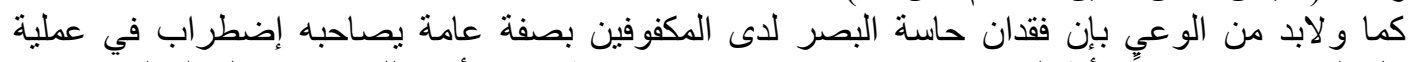

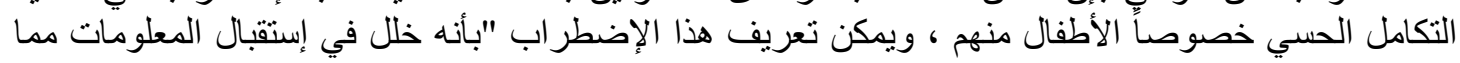

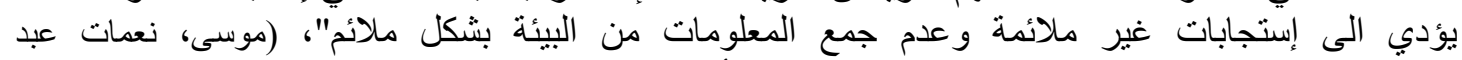

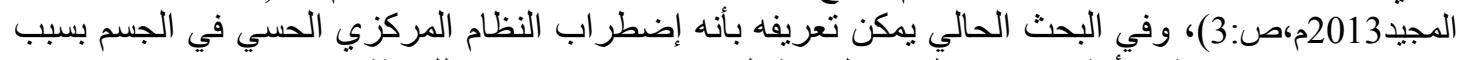

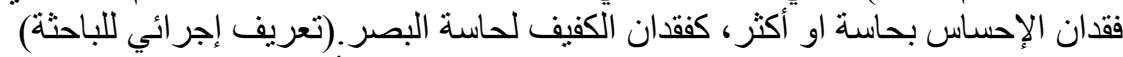

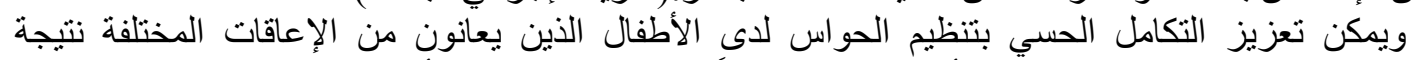

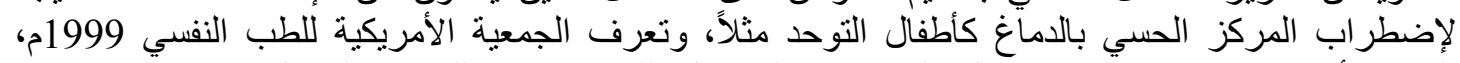

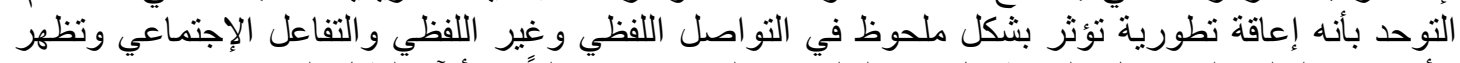

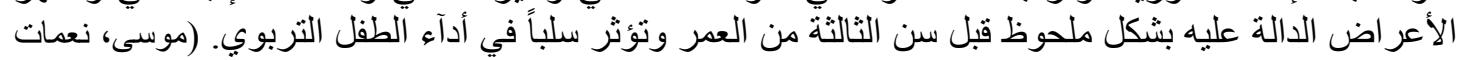

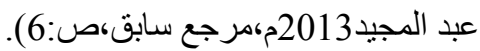
ولغرف التكامل الحسي Sensory room. أهمية كبرى ليس فقط للأطفال المصابين بالتوحد و إنما للكثير من

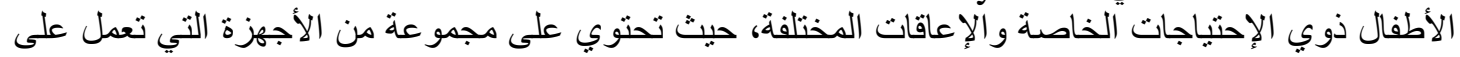

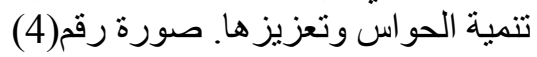

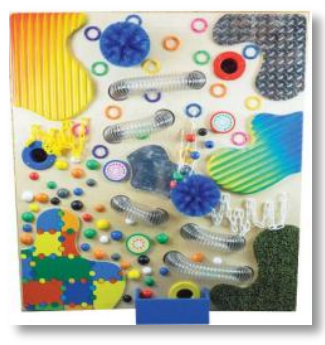

(ب)

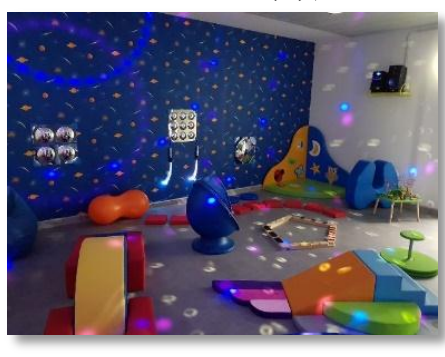

(أ)

صورة رقم (4) أب توضح بعض الملامس بغرفة التكامل الحسي التي تنمي الخبرات الحسية لحاسة اللمس ومعرفة الفروقات بينهميا

(https://www.taibahu.edu.sa/Pages/AR/News/NewsDetails.aspx?ID=6028) 


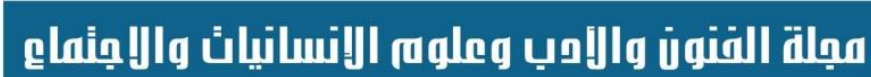 Journal of Arts, Literature, Humanities and Social Sciences \\ ISSN print: 2616- 3810 \\ ISSN online: 2414 - 3383 \\ Volume 48 January 2020 \\ ¿ALHSS www.jalhss.com

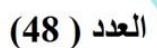 \\ يناير 2020}

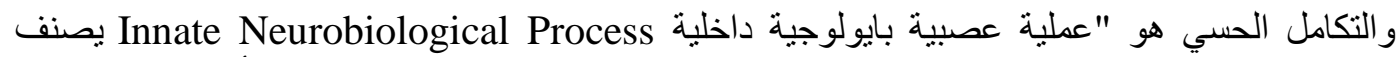

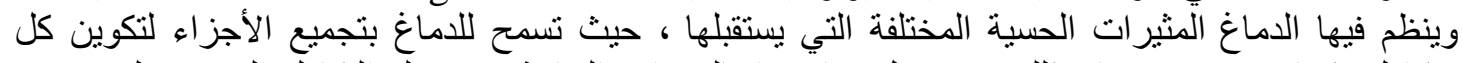

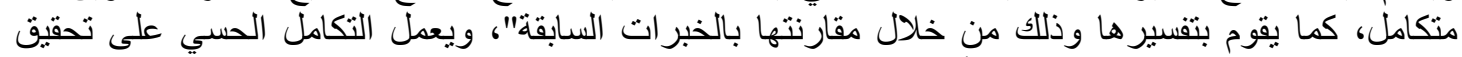

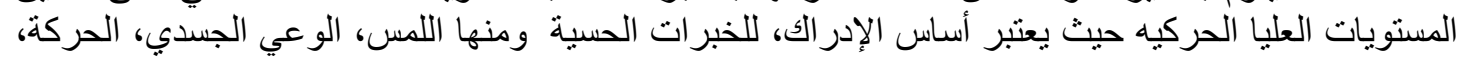

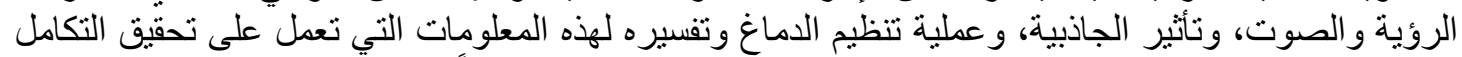

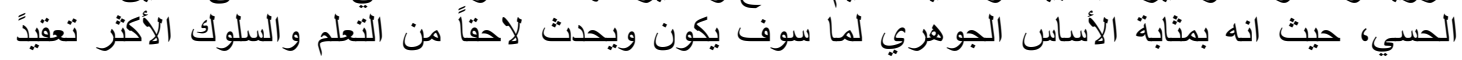

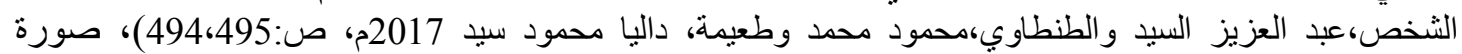

رقم)(5)

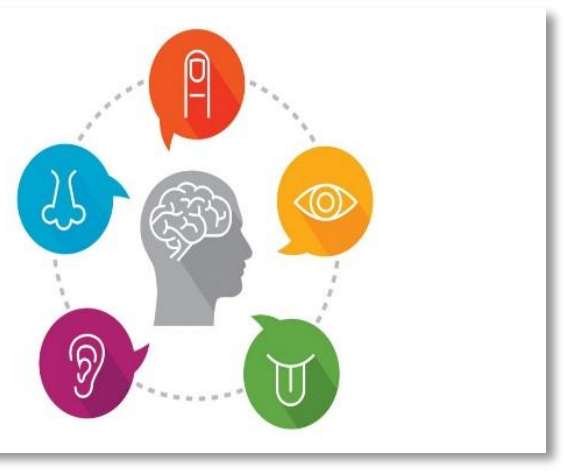

صورة رقم (5) توضح الخبرات الحسية من اللمس، التذوق، الروئة، الصوت، والثم ، وعملية تنظيم الاماغ

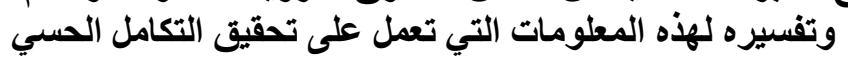

(https://maxcreativo.com/2019/06/18/marketing-sensorial/ )

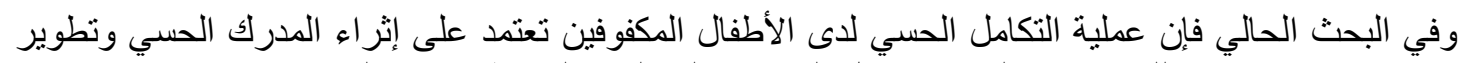

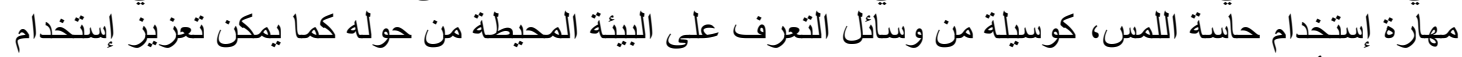

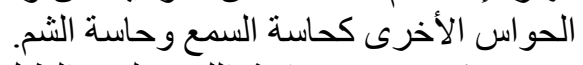

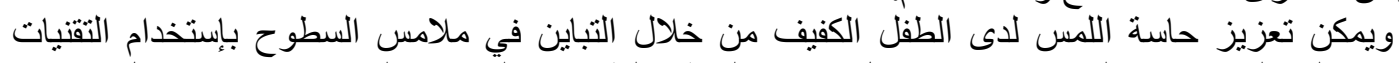

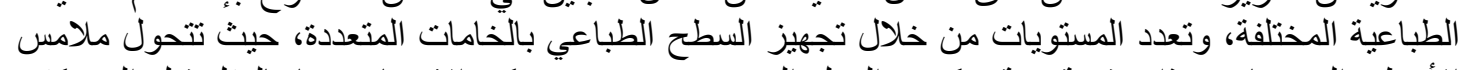

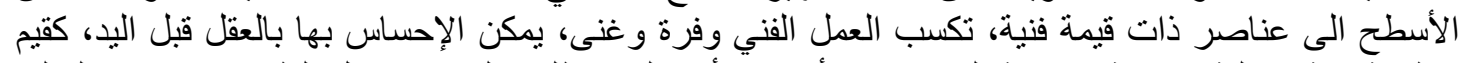

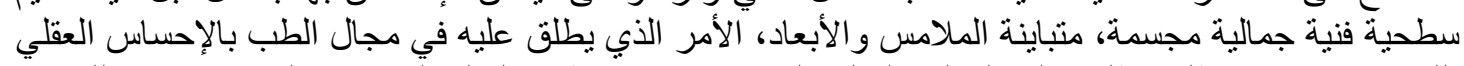

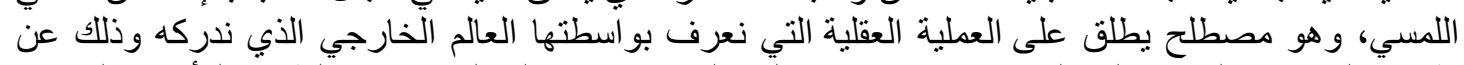

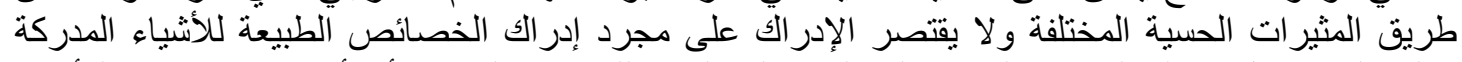

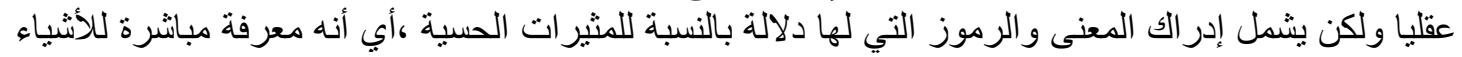

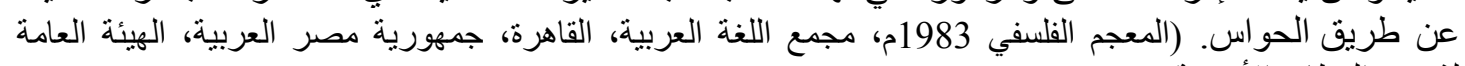

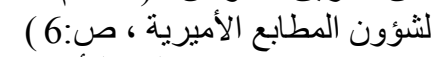

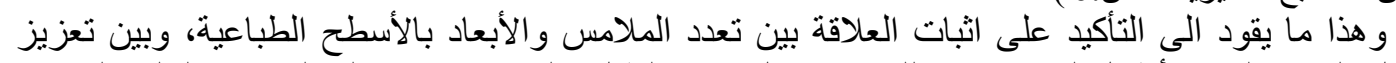

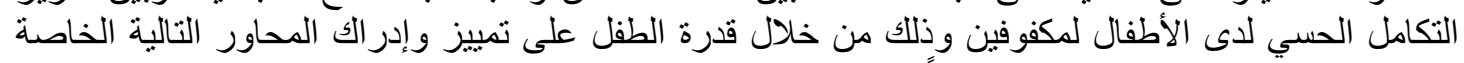

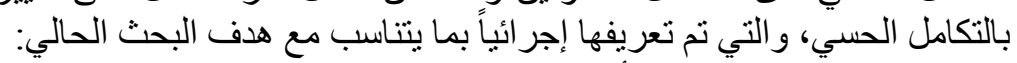

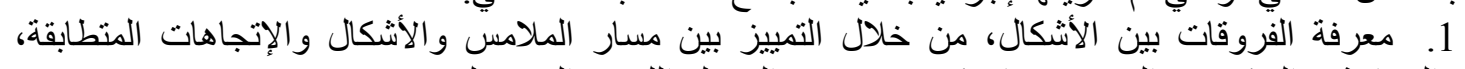

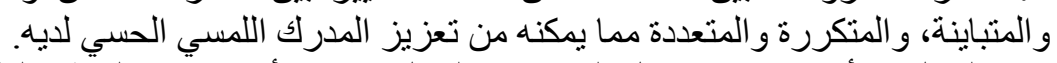

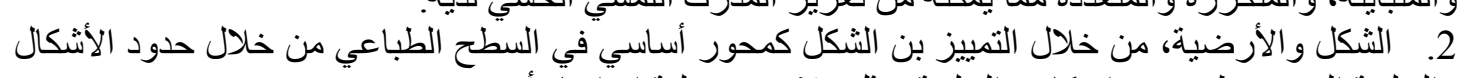

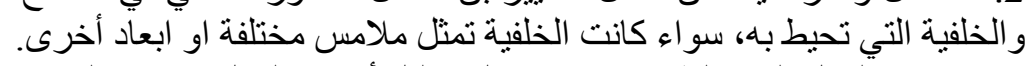

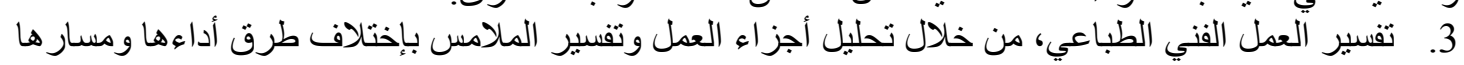

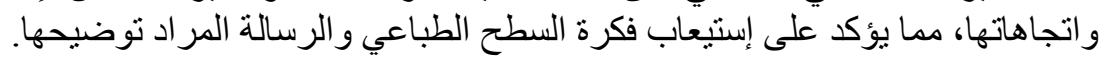




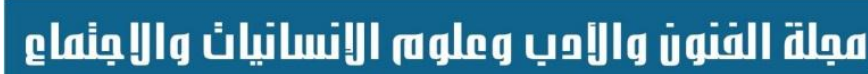 Journal of Arts, Literature, Humanities and Social Sciences \\ ISSN print: 2616- 3810 \\ Volume 48 \\ ISSN online: 2414 - 3383 \\ January 2020 \\ LALHSS

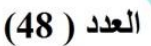 www.jalhss.com

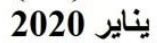

ويتناول الدحور التالي تحليلاً لأعمال فنية طباعية قائمة على تعزيز التكامل الحسي للأطفال المكفوفين من خلال الأسطح الطباعية المختلفة .

\section{ثالثاً: وصف وتحليل مختارات من الأعمال الفنية القائمة على الأسطح الطباعية متعددة}

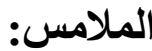

يقوم الفصل الحالي بتناول وصف وتحليل لمختار ات من أعمال الفنانين الطباعيين، ويتضمن هذا الفصل ما يلي: • • أولاً: هدف التحليل و الذي يمكن تلخيصه في النقاط التالية:

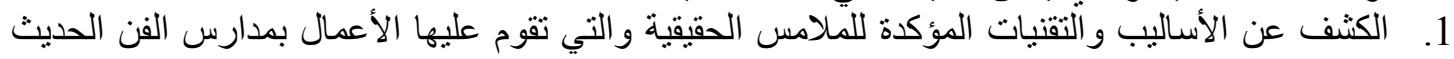

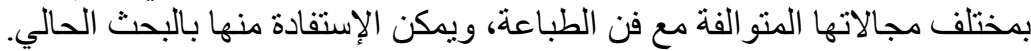

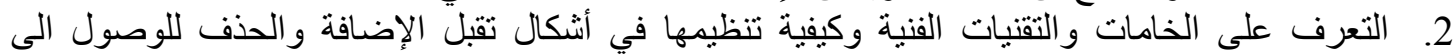

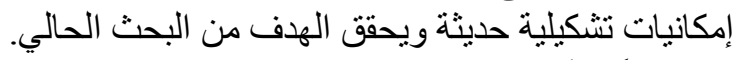

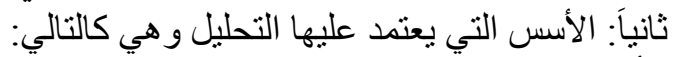

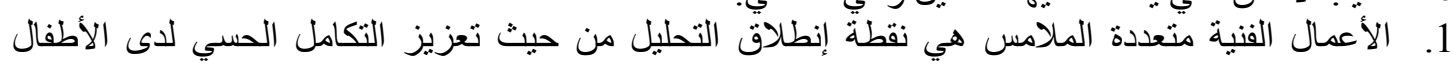
المكفوفين. 2. ت تتبع الأساليب و التقنيات و الخامات التي يقوم عليها العمل الفني الطباعي.

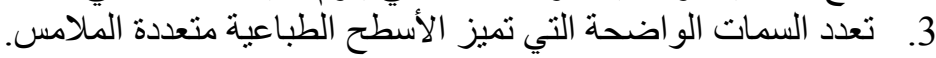

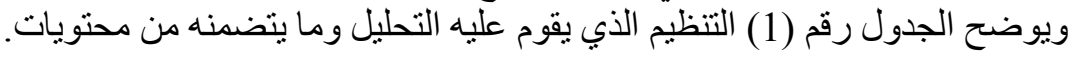

\begin{tabular}{|c|c|c|c|}
\hline تعزيز التكامل الحسي & آتشكيل & التقنيات & الخامات \\
\hline 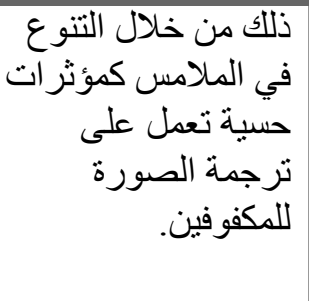 & 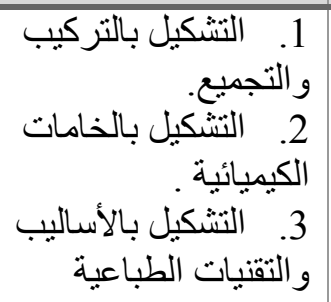 & الألقاليبي الطباعية والتقنيات & 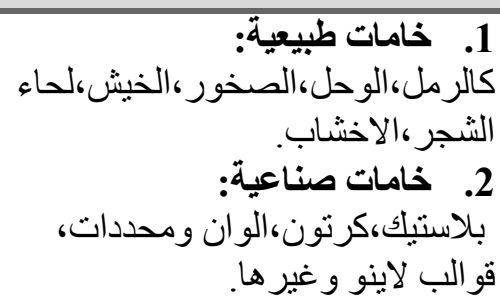 \\
\hline لجهس بالأسطح & الفة لفنانين تشنمل أعمال & 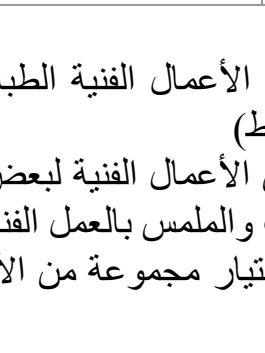 & 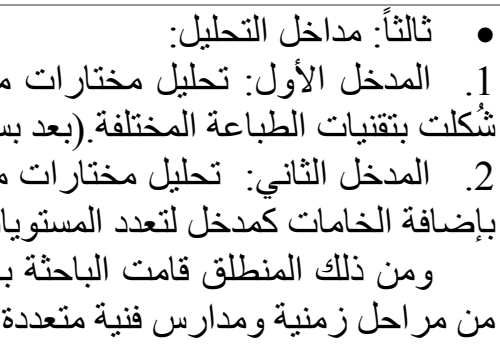 \\
\hline
\end{tabular}




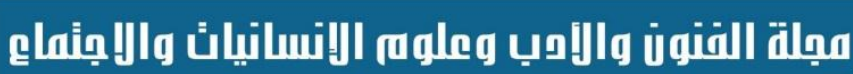 Journal of Arts, Literature, Humanities and Social Sciences \\ ISSN print: 2616- 3810 \\ ISSN online: 2414 - 3383 \\ Volume 48 January 2020 \\ ¿ALLHSS \\ العدد (48) (48) www.jalhss.com \\ يناير 2020}

المدخل الأول: تحليل مختارات من الأعمال الفنية لبعض الفنانين التي تثتتمل أعمالهم على ملامس بالأسطح

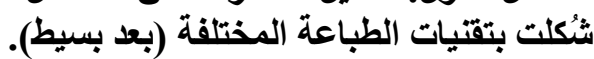

جدول رقم (2) تحليل العمل الطباعي الأول

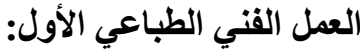

\begin{tabular}{|c|c|}
\hline وصف العمل القني & \\
\hline 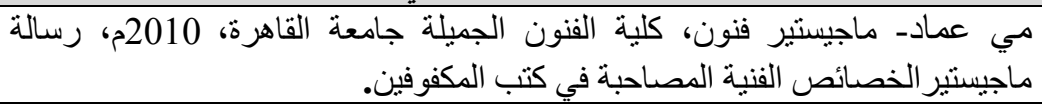 & إسم القنان \\
\hline ولنا في الخيال حياة "ملمس اللون" & إسم العمل \\
\hline القاهرة-2010م & مكان وتاريخ العمل \\
\hline 70سم 70x 120x & أبعاد العمل \\
\hline أسس تعليل العمل الفني من خلال الأسطح الطباعية متعددة الملامس & \\
\hline 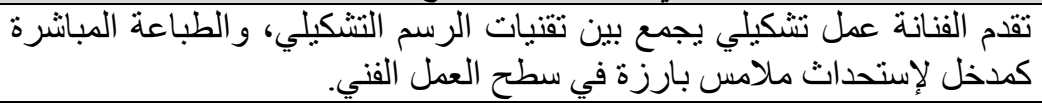 & التقتيات المستخدمة \\
\hline لوحات كانفس،الو ان إكليرك،محددات. & الخامات المستخدمة \\
\hline 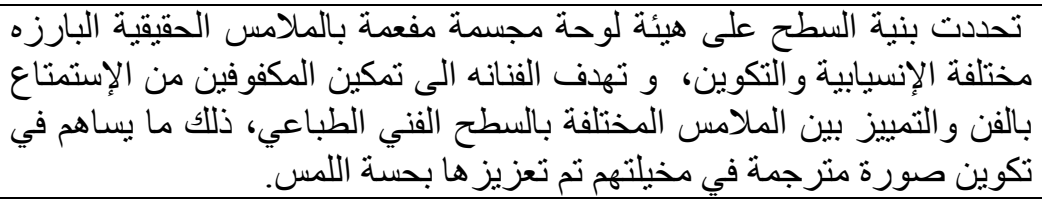 & توصيف التشكيل \\
\hline 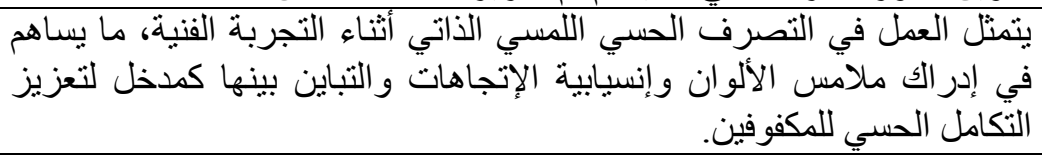 & تعزيز التكامل الحسي \\
\hline
\end{tabular}

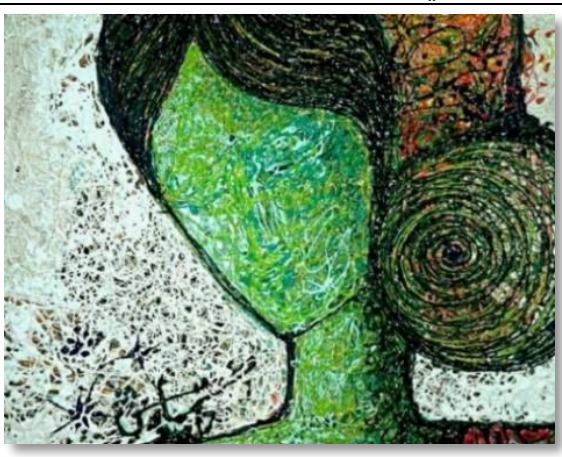

صورة رقم (6) توضح عمل فني تثكيلي تصويري بإسلوب الطباعة المباشرة وإضافة الملامس بارزة

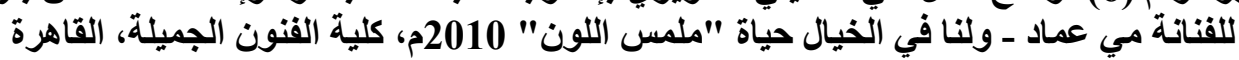
(http://facultyoffinearts.com/) 


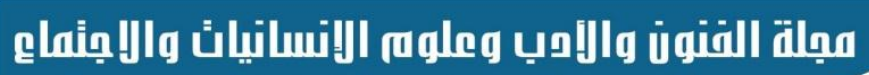 \\ Journal of Arts, Literature, Humanities \\ and Social Sciences}

ISSN print: 2616- 3810

Volume 48

ISSN online: 2414 - 3383

January 2020

¿ÁLHSS

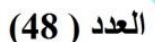

www.jalhss.com

يناير 2020

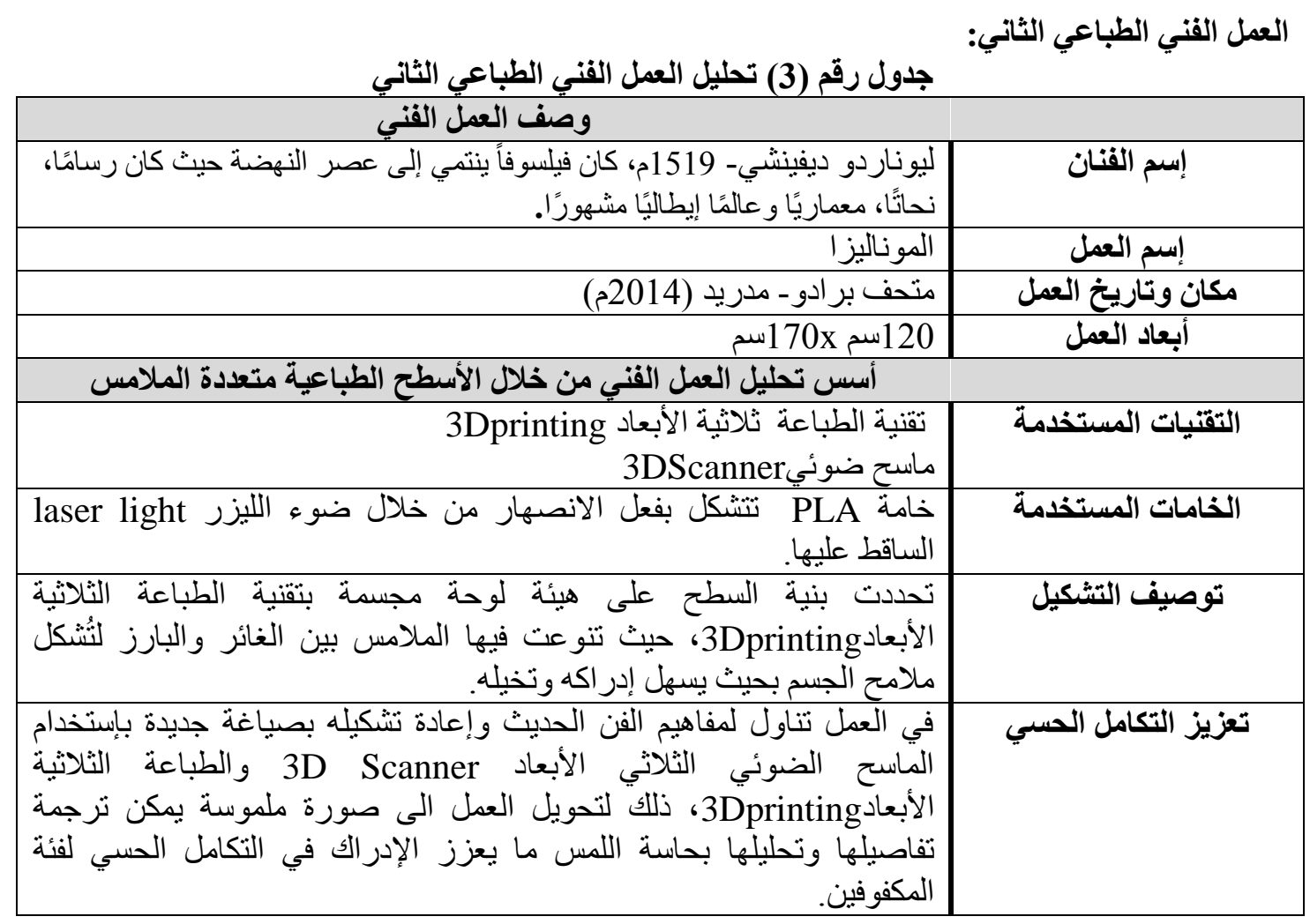

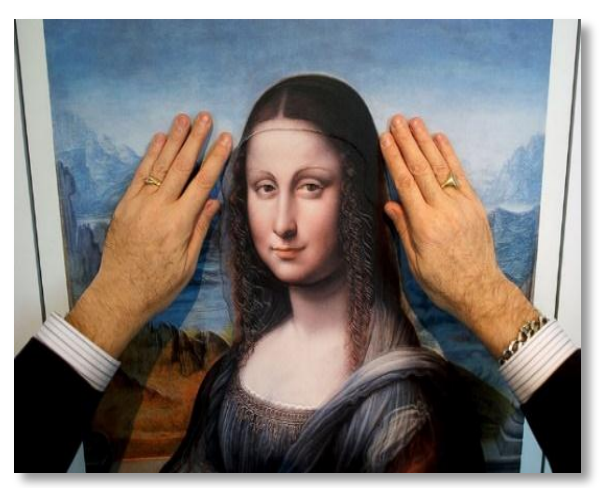

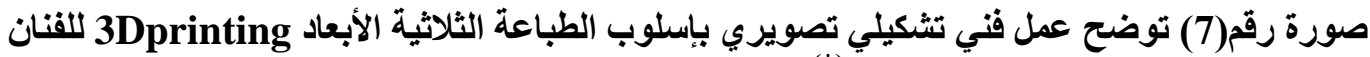

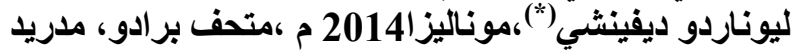

(https://www.museodelprado.es/en) 


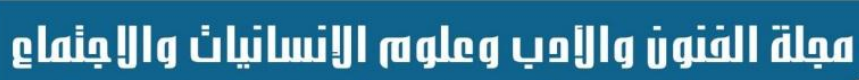

Journal of Arts, Literature, Humanities

and Social Sciences

ISSN print: 2616- 3810

Volume 48

ISSN online: 2414 - 3383

January 2020

(48) - العدد (48)

www.jalhss.com

يناير 2020

المدخل الثاني: تحليل مختارات من الأعمال الفنية لبعض الفنانين التي تثتتمل أعمالهم بمعالجات تثكيلية

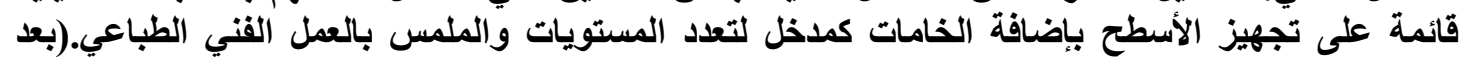

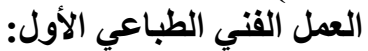

\begin{tabular}{|c|c|}
\hline وصف العمل الفني & \\
\hline عبد الو هاب مرسي- 1931م فنان مصري ولد في فاقوس، الثرقية. & إسم القنان \\
\hline الفن بين التبعية و الإستقلال & إسم العمل إل \\
\hline القاهرة 1982م & 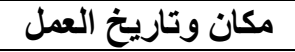 \\
\hline 190 x 150سم & أبعاد العمل \\
\hline أسس تعليل العمل الفني من خلال الأسطح الطباعية متعددة الملامس & \\
\hline 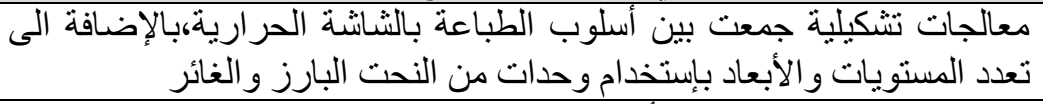 & التقتيات المستخدمة \\
\hline وحدات من الطين المنحوت، أحبار طباعة،شاشة حريرية،كانفس & الخامات المستخدمة \\
\hline 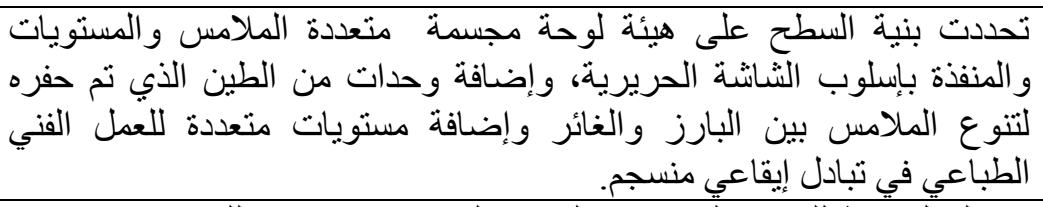 & توصيف التشكيل \\
\hline 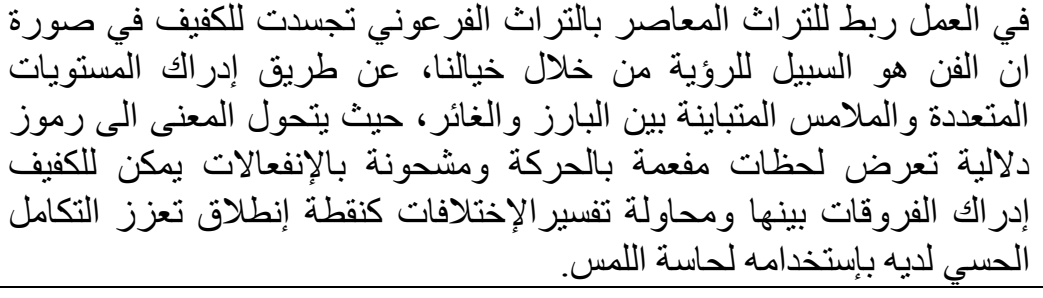 & تعزيز التكامل الحسي \\
\hline
\end{tabular}

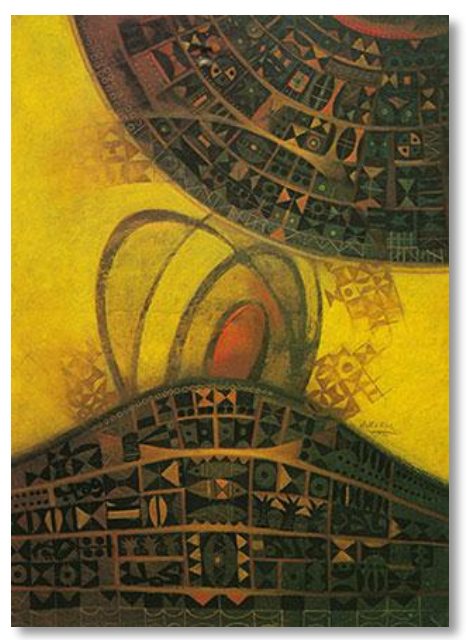

صورة رقم (9) توضح عمل فني طباعي بمعالجات تثكيلية جمعت بين أسلوب الطباعة بالثاشثة

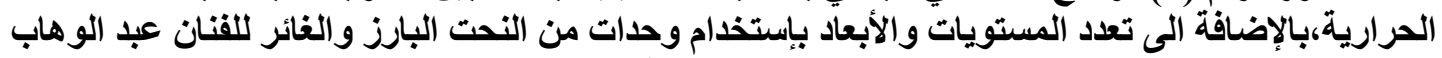
مرسي 1982م، الفن بين التبعية والإستقلال، القاهرة

(http://artmorsi.com/articlesAr.html) 


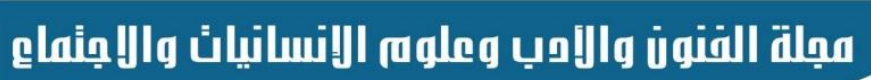 Journal of Arts, Literature, Humanities \\ and Social Sciences}

ISSN print: 2616- 3810

Volume 48

رابعاً: تجربة الباحثة القائمة على الأسطح الطباعية في تعزيز التكامل الحسي لاى الأطفال

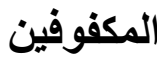

يتتاول هذا الفصل إجر اء تطبيقي للار اسة التي يعتمد على الإستفادة من معطيات الدراسة النظرية و التحليلية

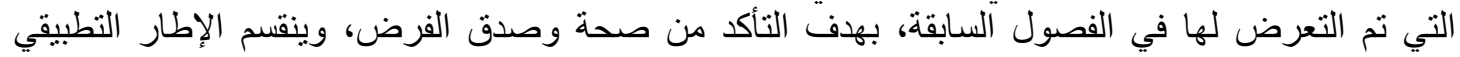

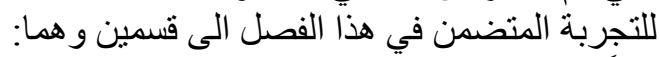
أولاً: تجربة إستكشاقية للباحثة:

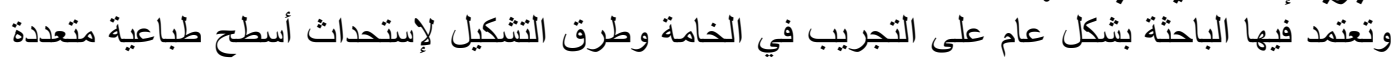
الملامس و المستويات تعزز التكامل الحسي لدئ لإى الأطفال المكفوفين.

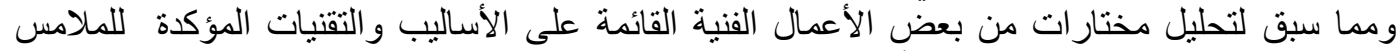

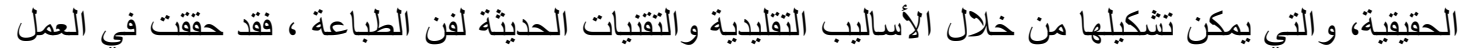

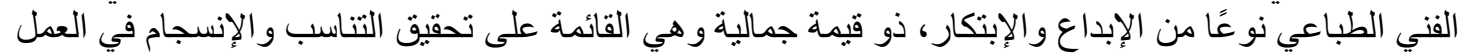

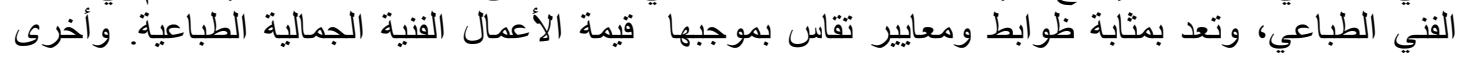

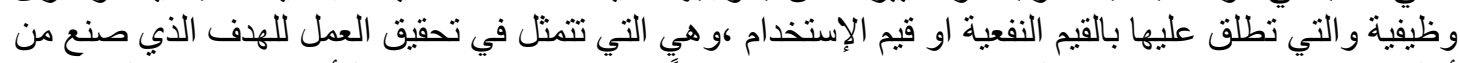

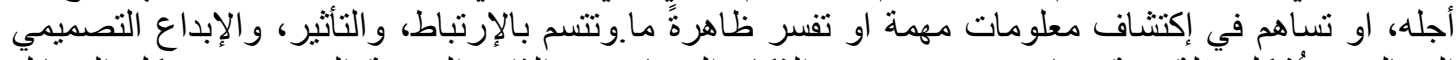

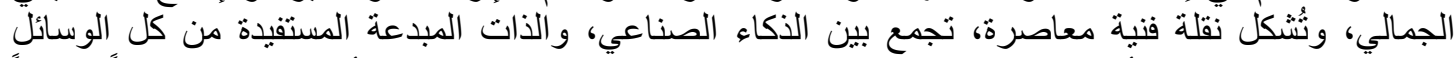

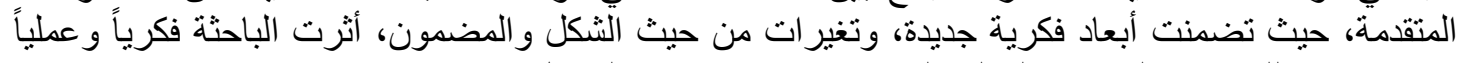
مما نتج عن ذلك بعض التجارب العملية التي يمكن توضيحها في الجدول رقم (5):

جدول رقم (5) الأسطح الطباعية متعددة الملامس وما يقابلها من تقنيات و أساليب طباعية

\begin{tabular}{|c|c|}
\hline التقتيات والأساليب الطباعية & الأسطح الطباعية متعددة الملامس \\
\hline 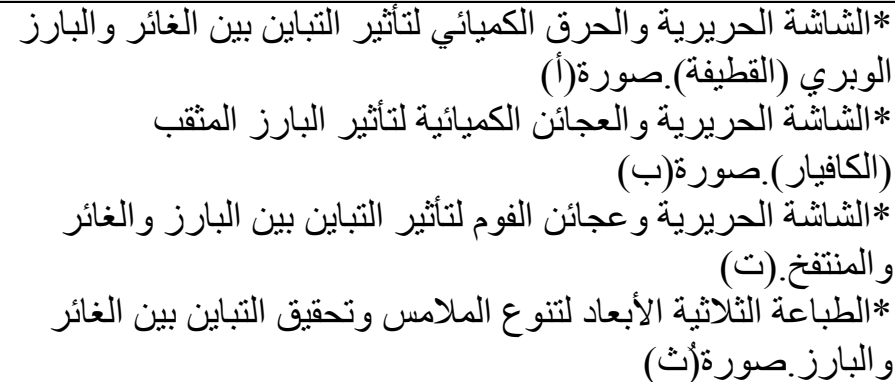 & المختلفة الملامس من خلال تقنيات الطباعة \\
\hline 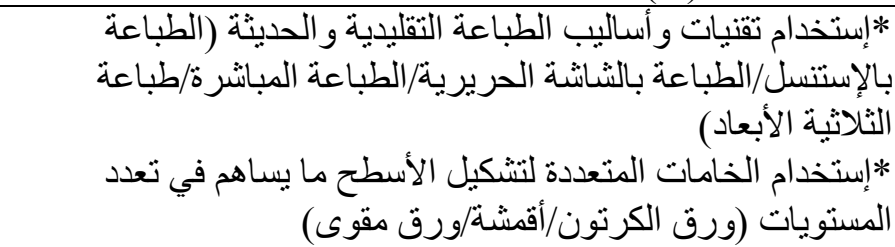 & تعلدد مستويات السطح والتباين في \\
\hline
\end{tabular}




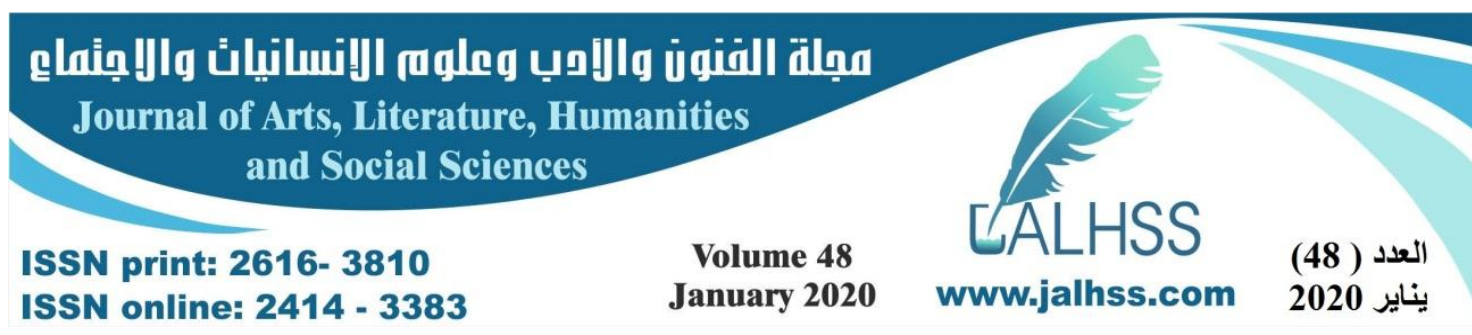

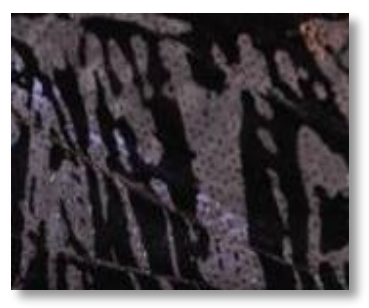

$(\varphi)$

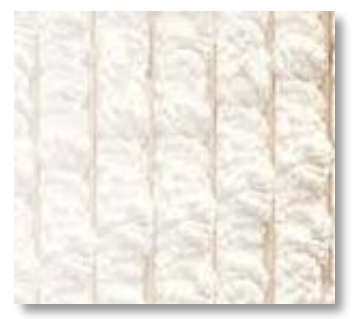

(ث)

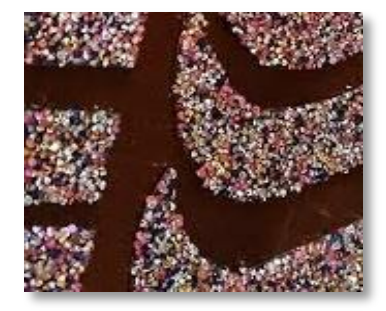

( ()

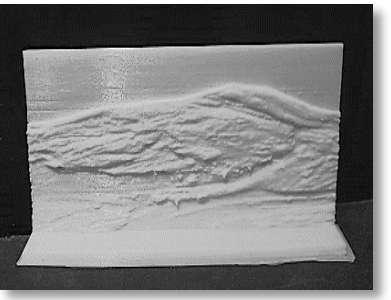

(ت)

صورة رقم (10) توضح تجربة الباحثة في إستحداث أسطح طباعية تثكلت فيها الملامس بالمعالجات التشكيلية المختلفة:

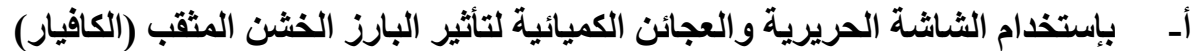

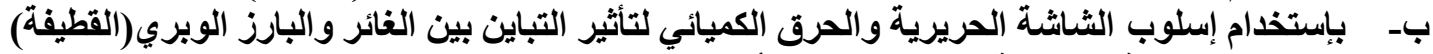

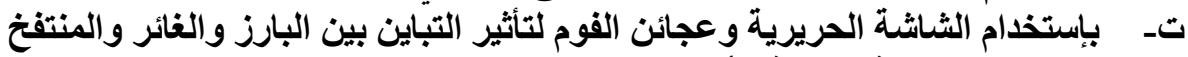

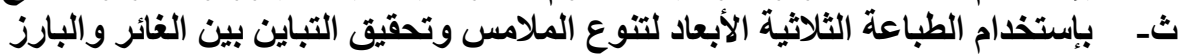

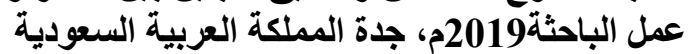

ثانياً: التجربة التطبيقية:

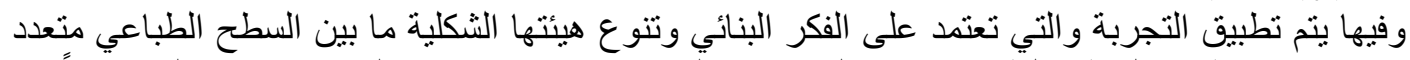

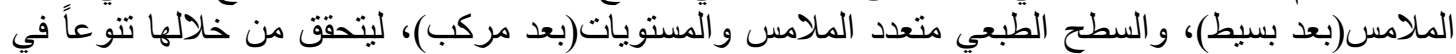

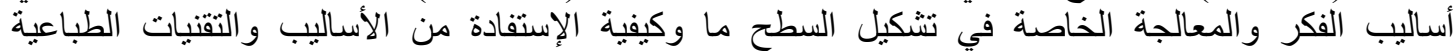

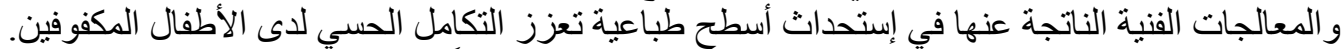

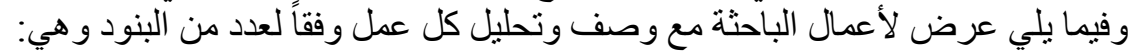

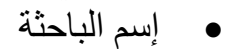

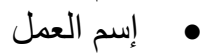

$$
\text { • }
$$




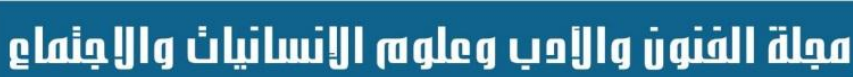 Journal of Arts, Literature, Humanities and Social Sciences \\ ISSN print: 2616- 3810 \\ Volume 48 \\ ISSN online: 2414 - 3383 January 2020 \\ العدد (48) www.jalhss.com \\ يناير 2020}

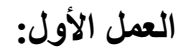

جدول رقم (6) تحليل العمل الفني الطباعي وصف العمل الفني الطياعي

\begin{tabular}{|c|c|}
\hline وصف العمل القني & \\
\hline ماجيستير فنون إسلامية جامعة الملكي عبد العزيز. & إسم الفنان \\
\hline مجسم جبل جُمّدان & 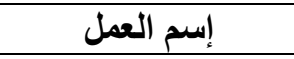 \\
\hline معرض الحديقة الثقافية بجدة-2018م & مكان وتاريخ العمل \\
\hline 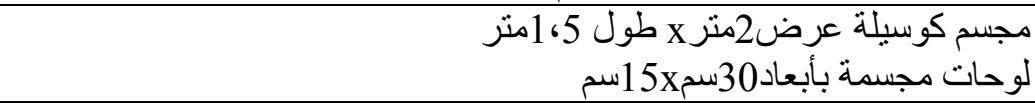 & أبعاد العمل \\
\hline \multicolumn{2}{|l|}{ أسس تعليل العمل الفني من خلال الأسطح الطباعية متعددة الملامس } \\
\hline 3Dprinting تقنية الطباعة ثلاثية الأبعاد & التقتيات المستخدمة \\
\hline خامة البلاستيك الملونة التي تتشكل بفعل الإنصهار من خلال ضوء اليزر & الخامات المستخدمة الخدات \\
\hline تحددت بنية السطح على هيئة مجسم ثلاثي الأبعاد & توصيف التشكيل \\
\hline 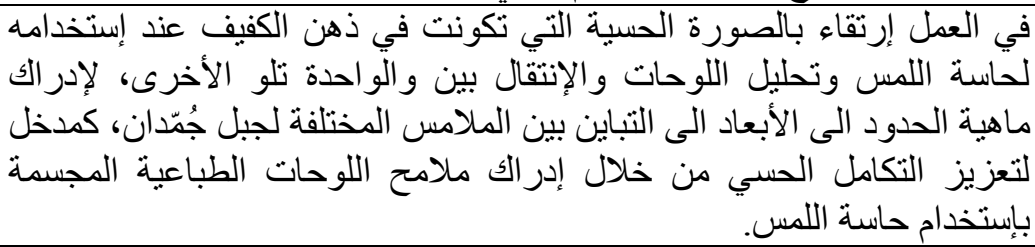 & تعزيز التكامل الحسي \\
\hline
\end{tabular}

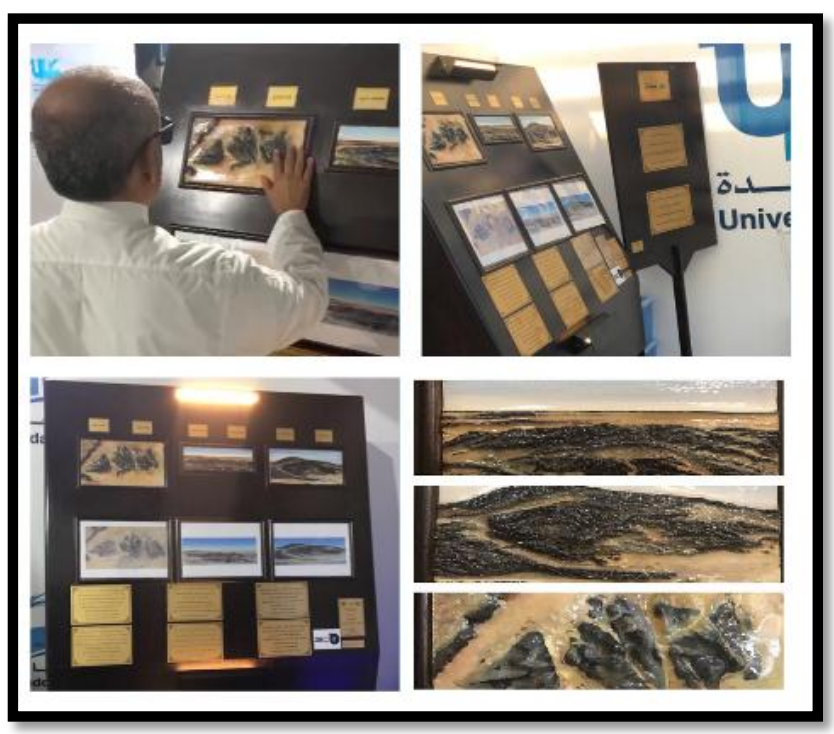

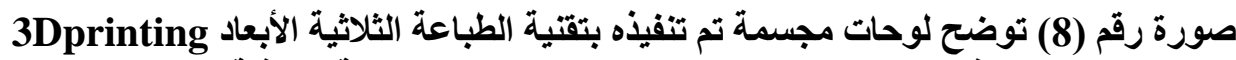

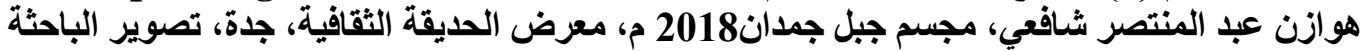
(https:// /CAjJVSGuPtajDvke7) 


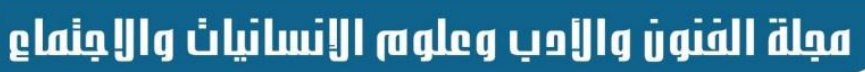 \\ Journal of Arts, Literature, Humanities \\ and Social Sciences}

ISSN print: 2616- 3810

ISSN online: 2414 - 3383
Volume 48 January 2020
LALHSS

www.jalhss.com

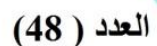

يناير 2020

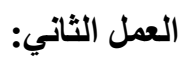

جدول رقم (7) تحليل العمل الفني الطباعي

\begin{tabular}{|c|c|}
\hline وصف العمل القني & \\
\hline جده، ماجيستير فنون إسلامية جامعة الملكي عبد البد العزيز. دكتور اه كلية التصاميم و الفنون جامعة & إسم القنان \\
\hline 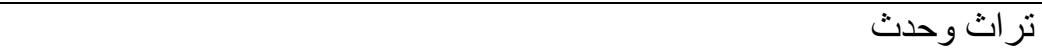 & إسم العمل \\
\hline جدة 2017م & مكان وتاريخ العمل \\
\hline 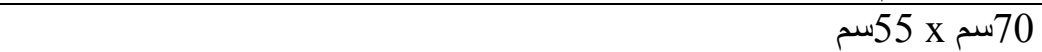 & أبعاد العمل \\
\hline أسس تحليل العمل الفني من خلال الأسطح الطباعية متعددة الملامس & \\
\hline 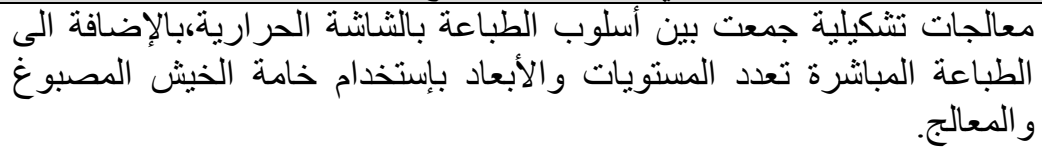 & التقتيات المستخدمة \\
\hline إكليرك، خبش معالج، أحبار طباعة،شاثـة حريرية، محددات فوم حرارية، الوان & الخامات المستخدمة \\
\hline 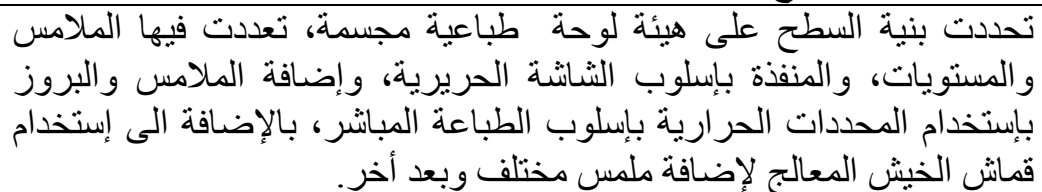 & توصيف التشكيل \\
\hline 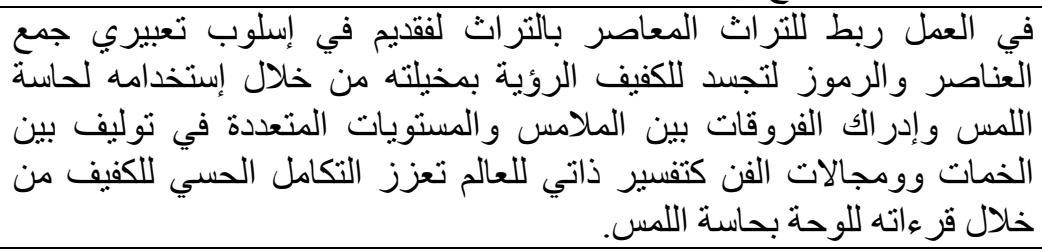 & تعزيز التكامل الحسي \\
\hline
\end{tabular}

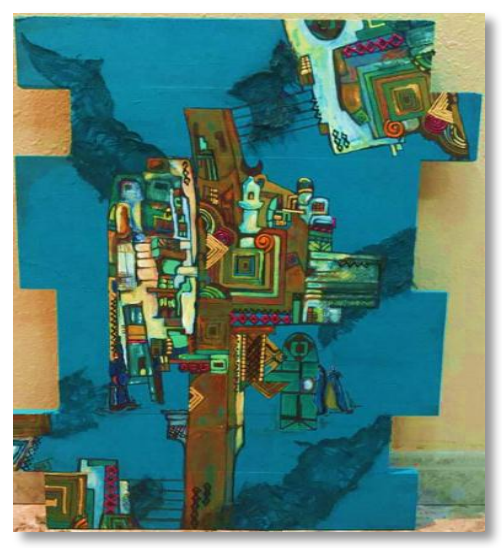

صورة رقم (10) توضح عمل فني طباعي بمعالجات تثكيلية جمعت بين أسلوب الطباعة بالثاثة الحرائة الحبارية،

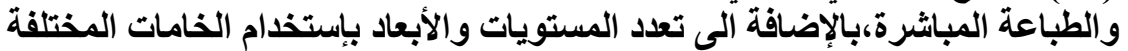

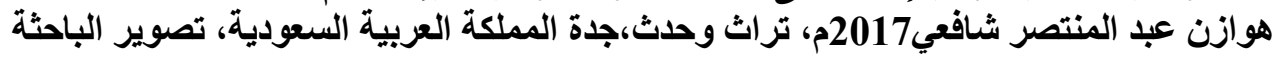




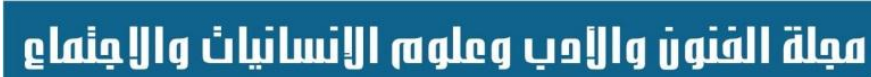 Journal of Arts, Literature, Humanities \\ and Social Sciences \\ ISSN print: 2616- 3810 \\ ISSN online: 2414 - 3383 \\ Volume 48 \\ January 2020 \\ LALLHS \\ www.jalhss.com

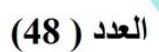 \\ يناير 2020}

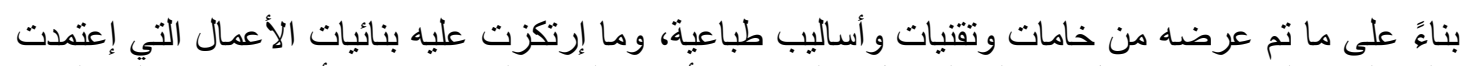

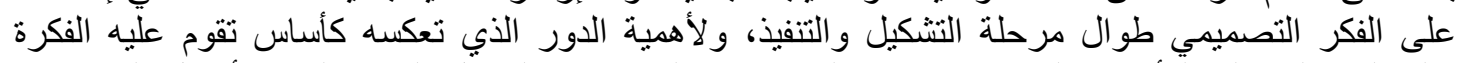

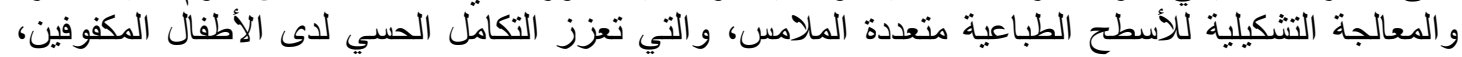

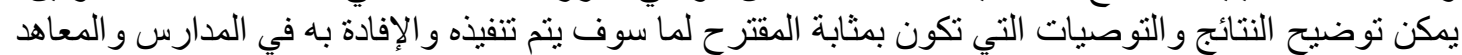
و الجمعيات القائمة على خدمة المكفوفين وتطوير قدر اتهم، بالمملكة العربية السعودية، وفي العالمالم أجمع .

النتائج والتوصيات:

النتائج:

1. إمكانية تعزيز التكامل الحسي لدى الأطفال المكفوفين من خلال الملامس والأبعاد المتعددة بالأسطح الطباعية.

2. الن التوليف بين التقنيات والأساليب الطباعية وبين المعالجات التشكيلية المتعددة، يحقق حلول تشكيلية

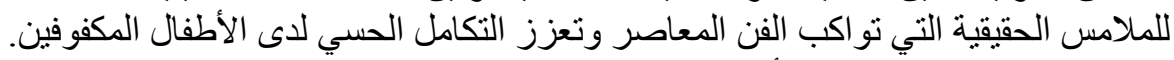

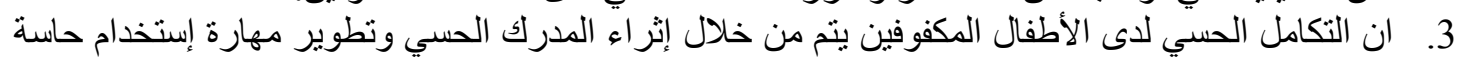

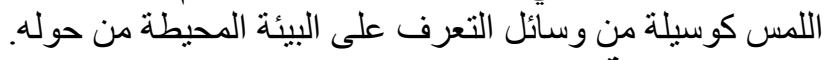

توصي الباحثة بالتالي:

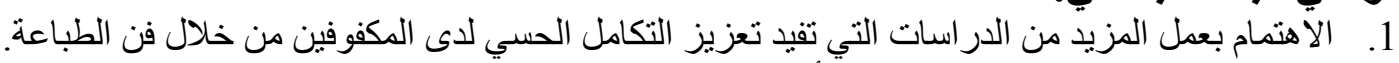

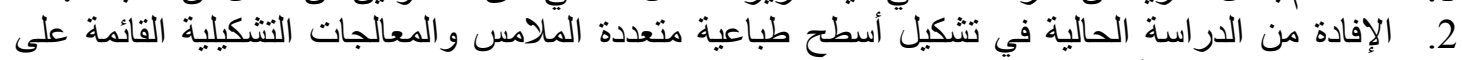

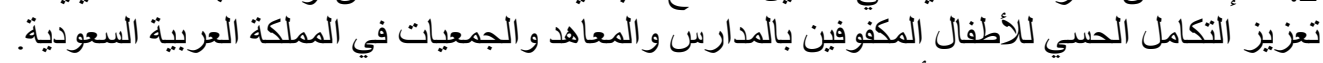

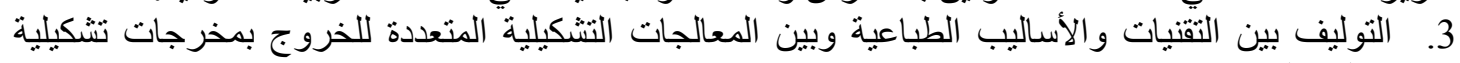
تو اكب الفن المعاصر.

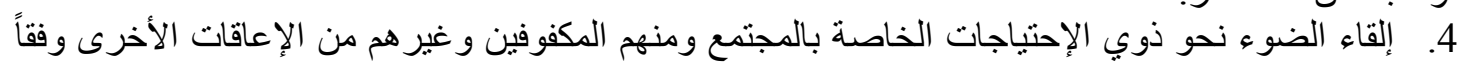

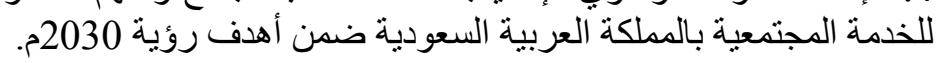

الكتب العربية:

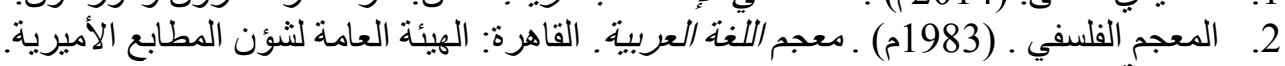

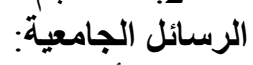

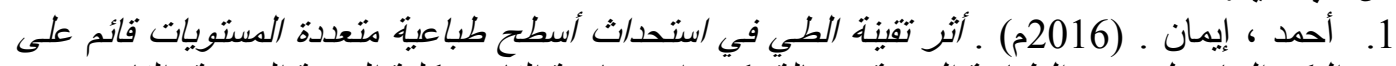

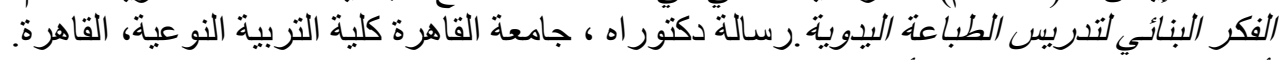

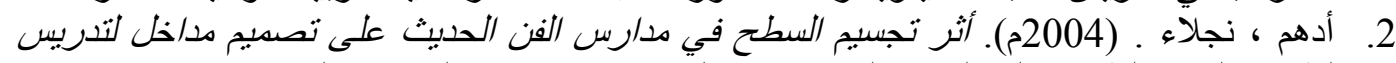

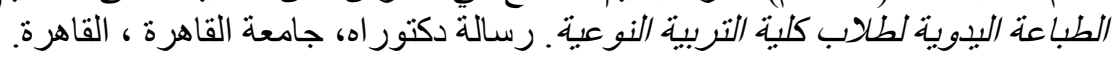

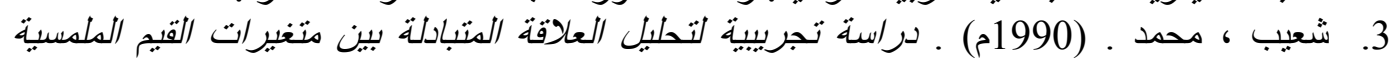

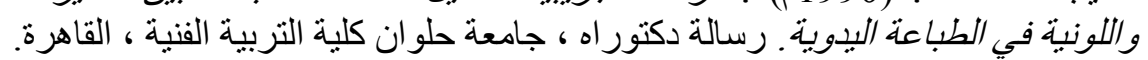

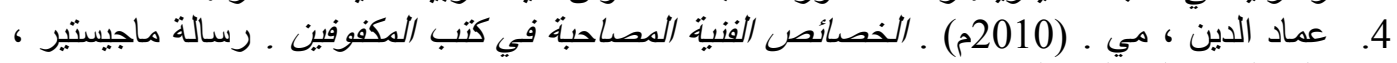
كلية الفنون الجميلة ، القاهرة.

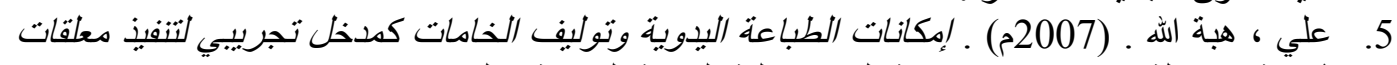

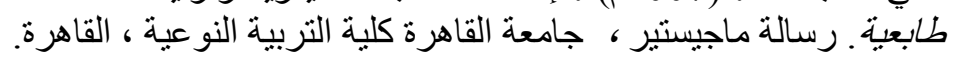

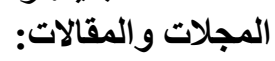

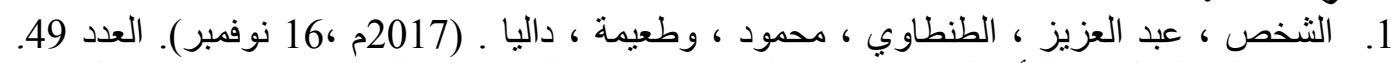

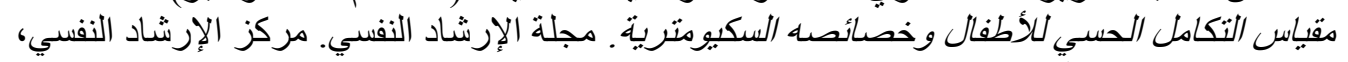
جامعة عين شمس، القاهرة.

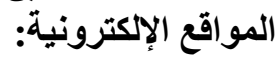




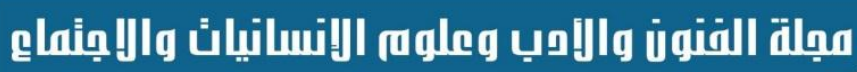 \\ Journal of Arts, Literature, Humanities \\ and Social Sciences}

ISSN print: 2616- 3810

Volume 48

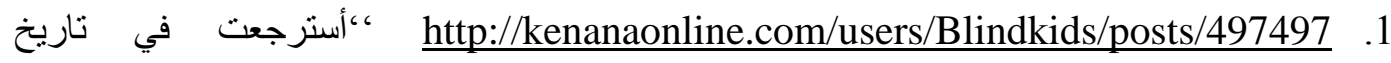

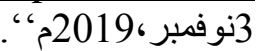

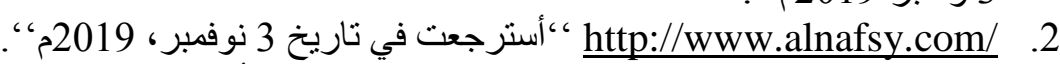
3 3

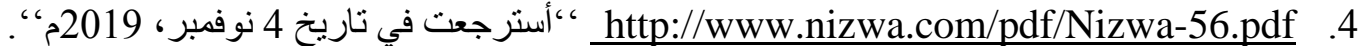
6

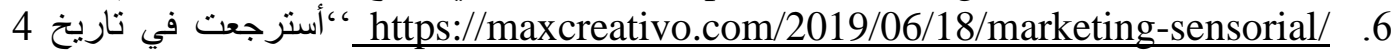

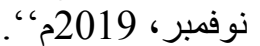

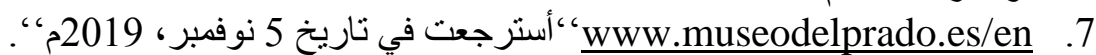
8

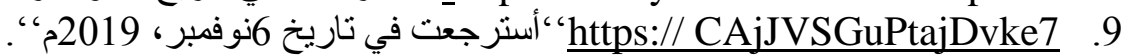

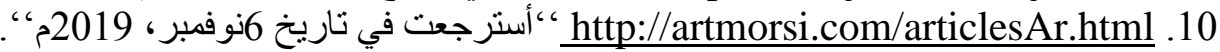

\section{References}




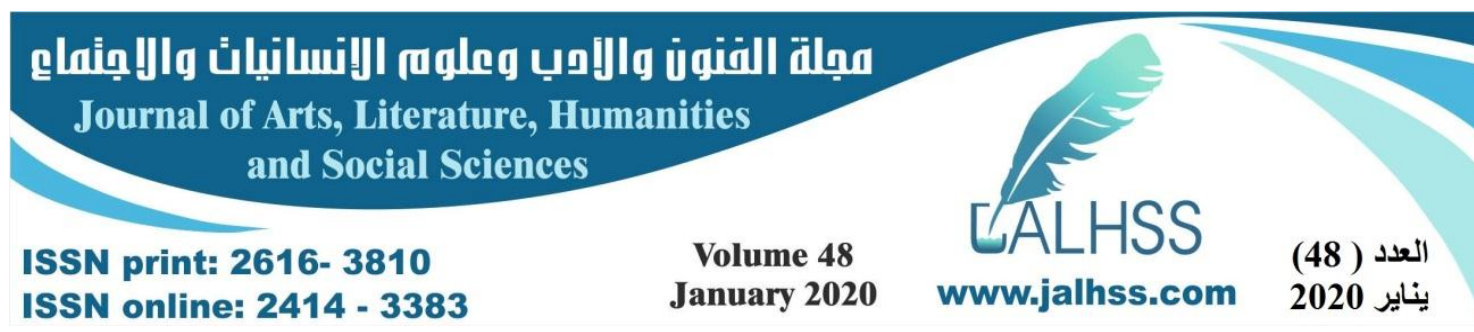

1. Al-Hadidi, M. (2014 ). Introduction To Visual Impairment. Amman: Dar AlFikr Publishers and Distributors.

2. . Philosophical Lexicon. (1983 ). A dictionary of the Arabic language. Cairo: The General Authority of Emiri Printing Press.

3. Ahmed, I. (2016). The effect of folding technology on creating multi-level printing surfaces based on constructive thought to teach manual printing. Ph.D., Cairo University, Faculty of Specific Education, Cairo.

4. 2. Adham, N. (2004 ). The effect of surface embodiment in schools of modern art on designing entries for teaching hand print to students of the Faculty of Specific Education. $\mathrm{PhD}$ thesis, Cairo University, Cairo.

5. Shoaib, M. (1990). an experimental study to analyze the correlation between the variables of the physical and color values in manual printing. $\mathrm{PhD}$ thesis, Helwan University, Faculty of Art Education, Cairo.

6. Imad Al-Din, M. (2010). Accompanying technical characteristics in the books of the blind. Master Thesis, Faculty of Fine Arts, Cairo.

7. Ali, H. (2007 ). The Capabilities Of Manual Printing And Material Synthesis As A Pilot Input For The Implementation Of Printer Suspension. Master thesis, Cairo University, Faculty of Specific Education, Cairo.

8. AL Shike, A, Tantawi, Mahmoud, Tuaima, Dalia. (2017, November 16). Issue 49. The Scale of Sensory Integration of Children and its Psychometric Characteristics. The Journal of Psychological Counseling. Psychological Counseling Center, Ain Shams University, Cairo.

9. http://kenanaonline.com/users/Blindkids/posts/497497 "Retrieved on November 3, 2019".

10. http://www.alnafsy.com/ "Retrieved on November 3, 2019 ".

11. http://new.alnoor.se/article.asp?id=278402 "Retrieved on November 3, 2019 ".

12. http://www.nizwa.com/pdf/Nizwa-56.pdf "Retrieved on the date of November 4, $2019 "$.

13. https://www.instagram.com/artalrsheed/ "Retrieved on November 4, 2019 ".

14. https://maxcreativo.com/2019/06/18/marketing-sensorial/ "Retrieved on November 4, 2019 ".

15. www.museodelprado.es/en "Retrieved on November 5, 2019 ".

16. http://facultyoffinearts.com/https:// "Retrieved November 5, 2019 ".

17. http: // CAjJVSGuPtajDvke7 "Retrieved on November 6, 2019 ".

18. http://artmorsi.com/articlesAr.html "Retrieved on November 6, 2019 ". 